Check for updates

Cite this: RSC Adv., 2018, 8, 23130

\title{
Separation and purification using GO and r-GO membranes
}

\author{
J. Lyu, ${ }^{a}$ X. Wen, (DD ${ }^{a}$ U. Kumar, (D) ${ }^{a}$ Y. You, ${ }^{a}$ V. Chen (D) ${ }^{\text {b }}$ and R. K. Joshi (D) *a
}

Many materials with varied characteristics have been used for water purification and separation applications. Recently discovered graphene oxide (GO), a two-dimensional derivative of graphene has been considered as a promising membrane material for water purification due to its excellent hydrophilicity, high water permeability, and excellent ionic/molecular separation properties. This review is focussed on the possible versatile applicability of GO membranes. It is also known that selective reduction of GO results in membranes with a pore size of $\sim 0.35 \mathrm{~nm}$, ideally suited for desalination applications. This article presents the applicability of graphene-based membranes for multiple separation applications. This is indeed the first review article outlining a comparison of GO and r-GO membranes and discussing the suitability for applications based on the porosity of the membranes.

Received 13th April 2018

Accepted 14th June 2018

DOI: $10.1039 / \mathrm{c} 8 \mathrm{ra03156h}$

rsc.li/rsc-advances
In comparison to ceramic and polymeric membranes, the new class of membranes based on the recently discovered graphene oxide (GO) offers superior properties, such as high hydrophilicity, outstanding dispersion in water, nanopores, and excellent mechanical behaviour. ${ }^{9}$ Moreover, reduced graphene oxide (r-GO), another important derivative of graphene, with similar properties as GO has been used in membrane separation technology.

\subsection{Graphene oxide}

GO is an oxidized form of graphene (GN) that is considered to be the thinnest and strongest material with an extended oneatom-sheet of $\mathrm{sp}^{2}$-bonded carbon atoms. ${ }^{\mathbf{1 0 - 1 2}}$ Graphite oxide which was synthesized from the oxidization of graphite ${ }^{13}$ can be converted into graphene oxide via exfoliation in ultra-sonicator. ${ }^{14}$ This is to mention that, the Hummers method is the most common approach for synthesizing graphite oxide, as it offers a high yield. Hummers and Offeman ${ }^{15}$ used $\mathrm{KMnO}_{4}$, concentrated $\mathrm{H}_{2} \mathrm{SO}_{4}$, and $\mathrm{NaNO}_{3}$ as a mixture oxidant to oxidize graphite for a certain time, in which the intermediate product $\left(\mathrm{Mn}_{2} \mathrm{O}_{7}\right)$ is the main oxidant as shown in the equation taken from ref. 16:

$$
\begin{gathered}
\mathrm{KMnO}_{4}+3 \mathrm{H}_{2} \mathrm{SO}_{4} \rightarrow \mathrm{K}^{+}+\mathrm{MnO}_{3}^{+}+\mathrm{H}_{3} \mathrm{O}^{+}+3 \mathrm{HSO}_{4}^{-} \\
\mathrm{MnO}_{3}^{+}+\mathrm{MnO}_{4}^{-} \rightarrow \mathrm{Mn}_{2} \mathrm{O}_{7}
\end{gathered}
$$

Graphite oxide consists of layers of GO and can be used to prepare GO flakes via an ultrasonication process. ${ }^{15}$ GO has a defective graphene plane as well as various oxygen-containing functionalities, such as carboxyl, hydroxyl, and epoxy groups. ${ }^{17}$ The most widely recognized structure of GO is shown in

Fig. 2(b).
${ }^{a}$ SMaRT Centre, School of Materials Science and Engineering, University of New South Wales, Sydney, NSW 2052, Australia.E-mail: r.joshi@unsw.edu.au

${ }^{b}$ School of Chemical Engineering, University of New South Wales, Sydney, NSW 2052, Australia 


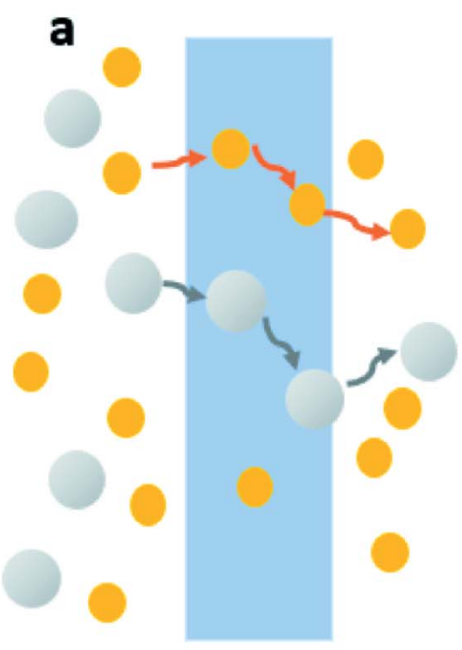

Dense membrane

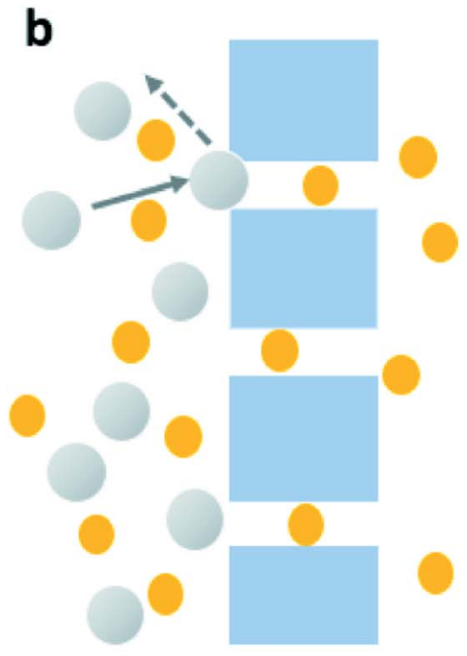

Porous membrane

Fig. 1 The transport mechanism for dense membranes (a) and porous membranes (b). Reproduced with permission from ref. 2. Copyright $\odot$ 2017, Royal Society of Chemistry. Reproduced with permission from ref. 4. Copyright@ 2010, John Wiley and Sons.

The unique structure of GO results in its superior characteristics. Due to the existence of oxygen groups, GO becomes hydrophilic, which could cause GO flakes to form homogenous dispersions with pure water and other polar organic solvents. Fig. 3 shows the stability and solubility of GO in organic solvents. ${ }^{18}$ Meanwhile, the non-oxidized regions of GO flakes are hydrophobic as pure graphene, which could explain that GO is an amphiphilic material. ${ }^{19}$ As a result, GO nanosheets perform similar to the surfactants tending GO to stay at the interface of two phases for reducing the free energy.

In addition, GO is likely to react with various chemicals to modify its properties. Also, the defects caused by the functional groups could be beneficial for the passage of water molecules. ${ }^{20-22}$
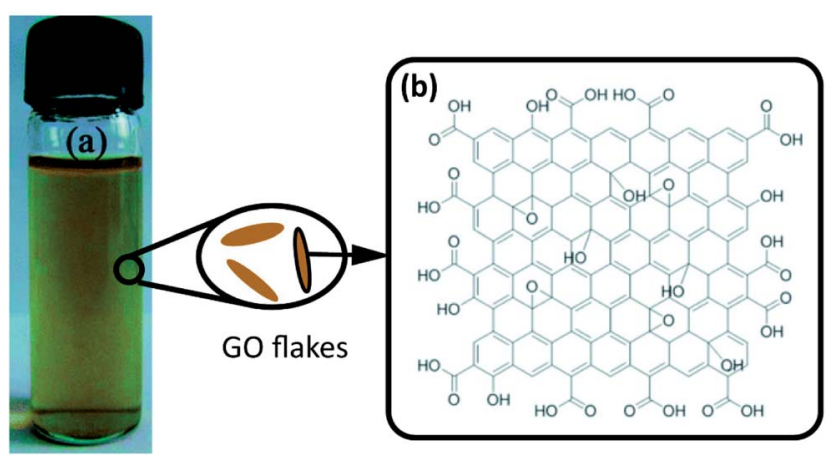

Fig. 2 (a) Graphene oxide suspension. Reproduced with permission from ref. 23. Copyright $\odot$ 2012, Royal Society of Chemistry. (b) The structure of GO according to the Lerf-Klinowski model. Reproduced with permission from ref. 17. Copyright $\odot 1998$ Elsevier Science B.V. Reproduced with permission from ref. 24. Copyright@ 2012, John Wiley and Sons.

\subsection{Reduced graphene oxide}

r-GO can be produced from GO by removing oxygen-carrying functionalities, which is also named as chemically modified graphene, functionalized graphene, chemically converted graphene, or reduced graphene. ${ }^{25}$ To date, the common reduction strategies include thermal reduction, chemical reduction, and solvothermal reduction. ${ }^{26}$

1.2.1 Thermal reduction. This method can further be divided into thermal annealing, microwave and photo irradiation. ${ }^{26}$ Reducing graphite oxide with a rapid heating $\left(>2000{ }^{\circ} \mathrm{C}\right)$ in a non-oxygen furnace is the thermal annealing method. In this process, two stacked GO flakes could be easily peeled off at a pressure of $2.5 \mathrm{MPa} .{ }^{27}$ Meanwhile, with the high pressure and high temperature, a large amount of $\mathrm{CO}$ and $\mathrm{CO}_{2}$ will be released through removing oxygen from the oxygen-containing functional groups and carbon from the GO's graphene-like region. As a result, wrinkled r-GO flakes are possible to be yielded by furnace heating. ${ }^{14}$ The thermal annealing is a highlyeffective GO reduction method, however, due to the release of $\mathrm{CO}$ and $\mathrm{CO}_{2}$, the graphene planes in r-GO nanoflakes prepared by the rapid annealing reduction could inevitably have an effect of structural damage, which leads to a lower conductivity in the $\mathrm{r}$-GO product than that of pure graphene and a resistance for heating GO membranes that are deposited on a low meltingpoint substrate material. Also, it is obviously an energyconsuming route because it needs a high reaction temperature. $^{28}$ In addition, with the development of novel heating methods, researchers have tried to synthesize r-GO with microwave- or photo-assistance, which can accelerate the reduction process. ${ }^{29} \mathrm{Zhu}$ et al. spent less than $1 \mathrm{~min}$ to achieve the exfoliation and reduction of GO with the assistance of a microwave. ${ }^{29}$ 

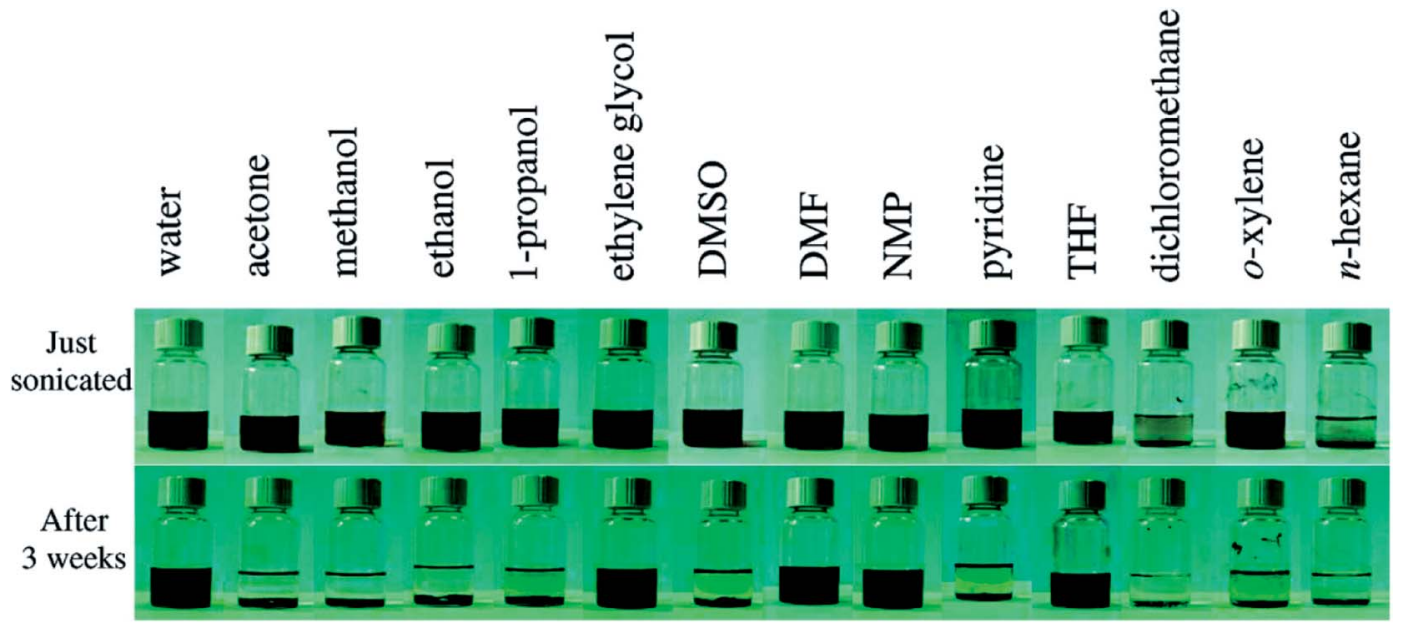

Fig. 3 Pictures of GO in water and other solvents after sonication for $1 \mathrm{~h}$. Reprinted with permission from (ref. 18). Copyright (2008) American Chemical Society.

1.2.2 Chemical reagent reduction. Adding chemical reducing agents is beneficial for the reaction in a moderate condition rather than a high temperature and high pressure as the thermal method needs. Moreover, this process can be achieved in a liquid environment. Conventional reagents are hydrazine, metal hydrides $\left(\mathrm{NaBH}_{4}\right)$, hydroiodic acid $(\mathrm{HI}), \mathrm{NaOH}$, etc. Stankovich et al. $^{30}$ firstly demonstrated that GO can be chemically reduced by hydrazine. Currently, hydrazine is considered as the most common reductant. Metal hydrides are the other important reagents for the synthesis of r-GO. Unlike hydrazine which can reduce various oxygen-containing groups in an aqueous environment, $\mathrm{NaBH}_{4}$ is a strong reducing agent only in organic solvents, reported by Periasamy et al. ${ }^{31}$ Meanwhile, Periasamy et al. ${ }^{31}$ also expressed that $\mathrm{NaBH}_{4}$ can reduce $\mathrm{C}=\mathrm{O}$ bond more effectively compared to other oxygen functionalities, such as carboxyl groups and epoxy groups. Pei et al. ${ }^{32}$ reported that $\mathrm{HI}$ can not only reduce GO membranes, but also maintain their stability. Even though many chemical reagents are toxic and non-environmentally friendly materials, this method is more energy efficient and more beneficial for the synthesis of r-GO membranes than the thermal reduction. Moreover, many researchers are gradually focusing on exploring green chemical reagents such as ascorbic acid (vitamin C), sugars, green tea, etc. ${ }^{33-35}$

1.2.3 Hydrothermal reduction. This reaction is another emerging reduction route, which is conducted in a sealed container at a certain temperature higher than boiling points of solvents. Under a high temperature condition, the concentration of $\mathrm{H}^{+}$in solution will be increased, which results in the reduction of GO sheets. Zhou et al. ${ }^{36}$ illustrated that GO can be converted to stable r-GO aqueous dispersion with hydrothermal method at $50{ }^{\circ} \mathrm{C}$. In this case, Zhou et al. ${ }^{36}$ also found that the GO suspension at $\mathrm{pH}=11$ could carry out r-GO solution, while an acidic GO solution ( $\mathrm{pH}=3$ ) tends to the aggregation of r-GO flakes. Xu et al. ${ }^{37}$ successfully produced porous r-GO hydrogel via hydrothermal method at $180^{\circ} \mathrm{C}$ for $12 \mathrm{~h}$. The prepared r-GO hydrogel offers excellent electrochemical properties. In comparison with the above two reduction strategies, therefore, hydrothermal reduction is a green method and its setup is extreme simple. Moreover, the other advantage is that this method can produce r-GO products with different phases, stable r-GO suspensions graphene hydrogels, which can increase the value of applications.

In comparison with GO, r-GO exhibits more $\mathrm{sp}^{2}$ hybridization. Fig. 4 is the TEM image of monolayer graphene, GO, and r$\mathrm{GO}$, respectively, which indicates that r-GO possesses a more graphene-like structure than GO. However, unlike the monolayer graphene, r-GO contains defects and oxygen-containing functional groups.

Due to the deoxygenation of graphene oxide, r-GO is less hydrophilic than GO. Therefore, an agglomeration phenomenon can easily take place when the highly reduced graphene oxide is dissolved into hydrophilic solvents. ${ }^{29}$ Surprisingly, various studies indicate that homogeneous r-GO aqueous dispersion could be synthesized. A successful study of r-GO colloid dispersion was demonstrated by Park and his coworkers. ${ }^{40}$ They obtained a well-dispersed r-GO aqueous solution by chemically reducing a GO suspension in a mixed solution of $\mathrm{DMF} / \mathrm{H}_{2} \mathrm{O}$.

In order to deeply understand the applications of GO and rGO membranes for gas separation and water purification, the following contents will demonstrate the conventional synthesis methods, the applications in waste water treatment, sea water desalination, and gas separation using the separation mechanism of GO and r-GO membranes.

\section{GO and r-GO membranes}

\subsection{Conventional synthesis methods for (r)GO-based membranes}

Generally, the common synthesis routes of (r)GO-based membranes include spin coating, layer-by-layer self-assembly, and vacuum filtration methods. Moreover, (r)GO composite membranes are commonly prepared by coupling the blending method and the above basic approaches. 

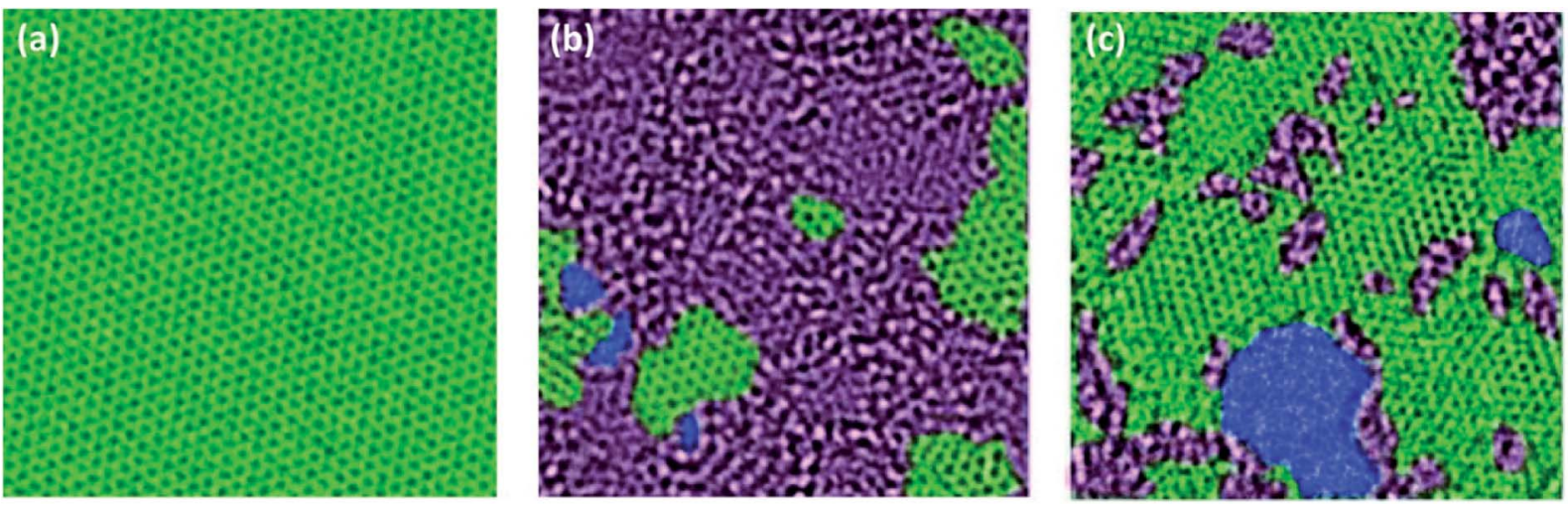

Fig. 4 Aberration corrected TEM images of graphene (a), GO (b), and $\mathrm{r}-\mathrm{GO}$ (c), in which the perfect sp ${ }^{2}$ carbon hybridization regions in green, the oxidized areas in grey, and the defects or pores in blue. Reproduced with permission from ref. 38. Copyright $\odot$ 2010, John Wiley and Sons.

2.1.1 Spin coating method. Spin coating is a widely used method for the fabrication of (r)GO-assisted membranes. ${ }^{\mathbf{4 1 4 2}}$ Commonly, the first step of spin coating is dropping GO suspension on a base. The second step is rotating the plate with high speed. Consequently, there will be a formation of thin liquid layer which is driven by a centrifugal force. ${ }^{43-45}$

Nair et al. ${ }^{46}$ synthesized ultrathin GO films with laminar structure by spin-coating method. They measured the distance between two laminates as $c a$. $10 \AA$. The GO semi-permeable membrane possessed an excellent selectivity. Wu et al. ${ }^{47}$ prepared excellent electrical reduced graphene oxide membrane by spin coating. Meanwhile, they adjusted the thickness of the fabricated membrane via changing the amount of reduced graphene oxide solution on the substrate. Becerril et al. $^{\mathbf{4 2}}$ compared the properties of different GO membranes prepared by three methods, spin-coating, drop-coating and solvent-induced precipitation. They used glass and quartz as substrate to fabricate GO films. As a result, the GO films fabricated by spin-coating were the thinnest among all products. Kim et $a{ }^{41}$ compared the structure of GO membranes which were synthesized by two spinning methods. In the method one, a polymeric substrate contacted GO solution with surface-bysurface. Thereafter, rotating the polymeric substrate facilitated in the removal of extra water resulting in the formation of a thin membrane (Fig. 5(a)). In the other method, a certain amount of GO solution was dropped on the base followed by the spinning (Fig. 5(b)). As a result, as-prepared GO membranes via the second process have a more dense and uniform structure than membranes synthesized by the first method, because water molecules could be removed more by the later approach decreasing the inter-layer spacing of GO membranes and increasing capillary interaction between GO layers. Chang et $a{ }^{48}{ }^{48}$ coated several layers $\mathrm{r}-\mathrm{GO}$ which was prepared by a low temperature thermal method, on a $\mathrm{SiO}_{2}$ substrate and the produced r-GO thin film have been used in the application of photodetection.

Spin coating method can easily adjust the thickness and area of membranes by controlling the amount of (r)GO solution and the size of the substrate.

2.1.2 Vacuum filtration. Vacuum filtration process is continuously filtering GO suspension with a strong vacuum pressure and depositing freestanding GO membranes. ${ }^{\mathbf{3 9 , 4 9 , 5 0}}$ Fig. 5(d) illustrates that lamellar GO sheets can be uniformly deposited by vacuum filtration. The continuous suction force from vacuum pump is able to move water rapidly, which contributes to a strong electrostatic repulsion among GO flakes to overcome the agglomeration of graphene oxide with the formation of ordered laminated GO membranes. ${ }^{24} \mathrm{Mi}^{21}$ reported pure GO membranes prepared by filtration in a vacuum condition are super tight, with an interlayer spacing of $\sim 0.3 \mathrm{~nm}$. The thickness, pore size and the spacing between GO nanosheets is tunable. ${ }^{21}$ Early in 2007, Dikin et al. ${ }^{49}$ synthesized graphene oxide membranes via vacuum filtration. The thickness of the prepared products was at a micron level ranging from 1 to $30 \mu \mathrm{m}$, while they had a high average tensile modulus of $32 \mathrm{GPa}$. Years later, Eda et al. ${ }^{\mathbf{1 1}}$ filtered graphene oxide colloidal solution through an ester membrane with pore size of $\sim 25 \mathrm{~nm}$ and obtained ultrathin GO films of $\sim 1 \mathrm{~nm}$. Joshi et al. ${ }^{52}$ immersed their fabricated GO membrane in an ionic solution which resulted in the increased interlayer spacings of $c a$. $0.9 \mathrm{~nm}$. Xu et al. ${ }^{53}$ filtered the mixed solution of $\mathrm{Ti}\left(\mathrm{SO}_{4}\right)_{2}$ and GO to obtain $\mathrm{GO} / \mathrm{TiO}_{2}$ composite membrane with an average pore size of $\sim 3.5 \mathrm{~nm}$. Moreover, You et al. ${ }^{54}$ applied various volumes of GO dispersion to form uniform GO membranes with different thicknesses that are from $<1 \mu \mathrm{m}$ to $c a .10 \mu \mathrm{m}$ on porous PVDF templates by vacuum filtration.

Han et al. ${ }^{55}$ deposited chemically reduced graphene oxide flakes by vacuum filtration. The thickness of as-prepared GO membranes was between 22-53 $\mathrm{nm}$ and its interlayer spacing decreased to $c a$. $0.4 \mathrm{~nm}$. By vacuum filtration, the thickness of GO films could be controlled easily. Yang et al. ${ }^{56}$ utilized HI vapours to chemically reduce their vacuum filtration prepared GO membranes for ions rejection application. Later, Yang ${ }^{57}$ enhanced the biofouling resistance property of the r-GO membranes. Recently, Zhang and his co-workers ${ }^{58}$ mixed oxidized carbon nanotube with r-GO dispersion which was synthesized by chemicals reduction, and the mixture solution was filtered for the deposition of rGO-OCNT membranes. Thebo et al. ${ }^{59}$ utilized vacuum filtration method to prepare $\mathrm{r}-\mathrm{GO} /$ tannic acid and r-GO/theanine amino acid composite membranes, and they found that all membranes can show a super water permeability ( $>10000 \mathrm{~L} \mathrm{~m}^{-2} \mathrm{~h}^{-1} \mathrm{bar}^{-1}$ ) and stability in water. 
(a)

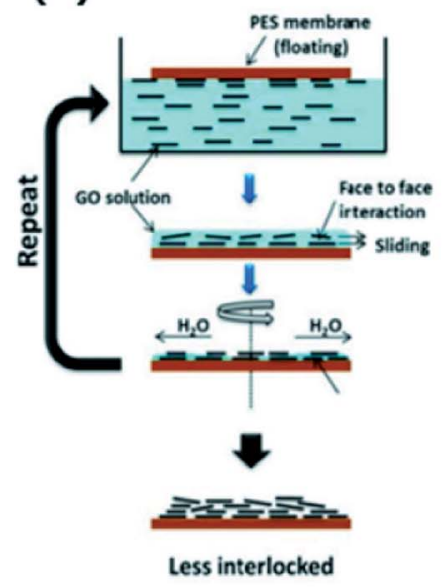

(b)

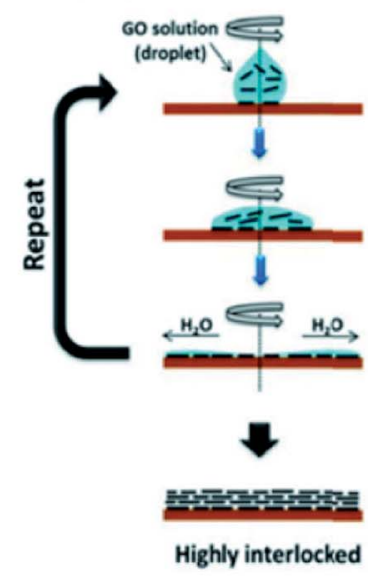

(c)
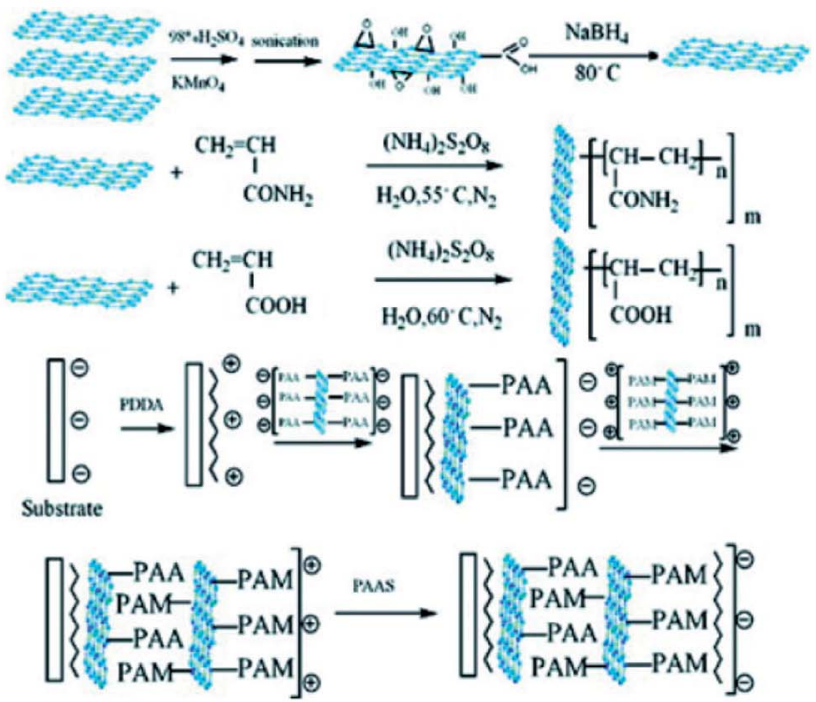
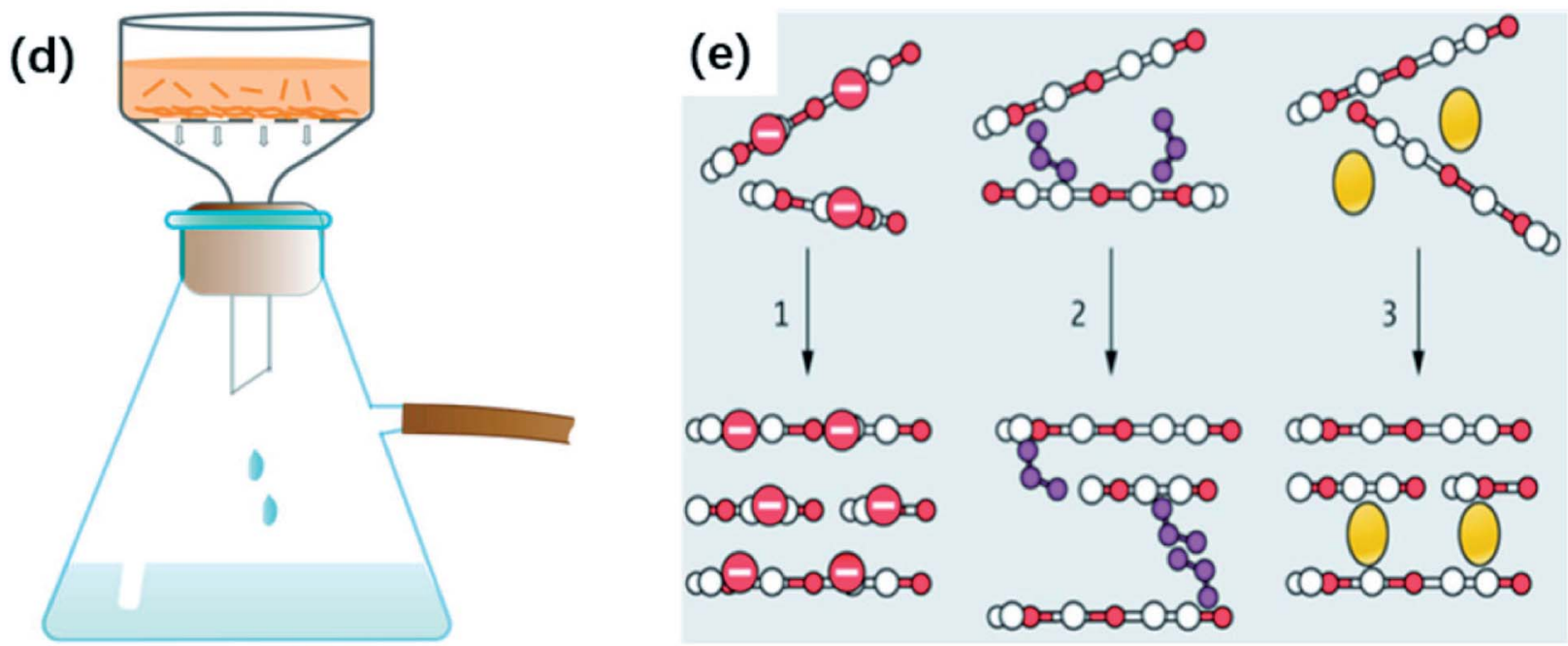

Fig. 5 (a) and (b) Preparation of GO membrane by two different spinning methods. Reproduced with permission from ref. 41 . Copyright@ 2013 , American Association for the Advancement of Science. (c) Synthetic process of a novel GO membrane by LBL self-assembly method. Reprinted with permission from (ref. 67). Copyright (2009) American Chemical Society. (d) Ordered deposition of GO sheets by vacuum filtration; (e) the mechanism of physically packed GO nanosheets by vacuum filtration. Reproduced with permission from ref. 21. Copyright@ 2014, American Association for the Advancement of Science.

To sum up, vacuum filtration method is easy to conduct, by which the thickness of membranes is controllable with adjusted concentration of GO suspension. However, GO papers are fragile when exfoliated from membrane base.

2.1.3 Layer-by-layer (LBL) self-assembly method. In this method, covalent bond and electrostatic interaction are the two main forces for the deposition of stable GO nanosheets. ${ }^{21}$ Due to the exitance of hydroxyl and carboxyl acid groups, GO flakes possess negative charge..$^{39,60,61}$ Therefore, there is a strong electrostatic attraction between positively charged substrate and negatively charged GO nanosheets, promoting the deposition of GO sheets. ${ }^{62}$ Furthermore, these functional groups can react with various compounds achieving the LBL assembly process. ${ }^{63-65}$ According to GO's amphiphilic characteristic, the hydrophilic substrates benefit the assembly of GO films because they facilitate the formation of one-layer water molecule between the bottom-layer's graphene oxide sheet with substrate, which benefits ordered deposition of GO membranes. ${ }^{24}$ Otherwise, the $\mathrm{pH}$ value of the solution can also influence the microstructure of stacked GO films prepared by LBL assembly method. It is possible to present wrinkles and overlaps connecting the adjacent GO sheets when the GO suspension is acidic. On the contrary, alkaline solution can tend GO to evenly stay in solution rather than at the surface because of the stronger repulsive force, which is beneficial to reduce wrinkles and overlaps. ${ }^{66}$

$\mathrm{Hu}$ and $\mathrm{Mi}^{65}$ prepared a novel GO membrane by LBL method. In this case, 1,3,5-benzenetricarbonyl trichloride acted as linker and the polydopamine-coated polysulfone worked as a support. They demonstrated that the GO membrane had a high flux which is about 4-10 times higher than that of most commercial membranes. Yu et al. ${ }^{62}$ deposited $\mathrm{GO}$ on a polyethyleneterephthalate (PET) base, where the prepared films merely had 
2-3 layers of reduced-GO sheets. Shen et $a l^{67}$ firstly synthesized GO-acrylic acid with negative charges and GO-acryl amide with positive charges. Due to the electrostatic interaction between GOacrylic acid and GO-acryl amide, they were successful to prepare laminar GO membrane by LBL self- assembly process, and the mechanism is demonstrated in Fig. 5(c).

Compared to vacuum filtration, LBL assembly method is more energy-saving. Meanwhile, the fabricated GO films are more stable than that prepared by vacuum pump.

2.1.4 Other methods. Plenty of alternative methods could be used for the fabrication of (r)GO membranes, such as drop coating, spray coating and dip coating. ${ }^{22,45}$ As for drop coating and spray coating, the main process of thin GO film formation is dripping or spraying GO dispersion on horizontal substrates and drying afterward. ${ }^{68}$ Gilje et al. ${ }^{69}$ spray-coated GO onto $\mathrm{SiO}_{2}$ substrate in which the prepared GO film is more uniform than that of drop-coating. Then, they chemical reduced the GO film with hydrazine at $80{ }^{\circ} \mathrm{C}$. Dip coating is another traditional film preparation method, in which the substrate should be withdrawn vertically from the container. After drying the substrate, a thin membrane can be fabricated. ${ }^{70}$

Furthermore, blending method is an important approach for hybridization of (r)GO and other components, which is beneficial to synthesize advanced GO composite membranes. Wang et al. ${ }^{71}$ synthesized a mixture of GO and polyvinylidene Fluoride (PVDF) solution by blending process and prepared GO-PVDF films via casting, which increased the pure water flux from $233.11 \mathrm{~L} \mathrm{~m}^{-2}$ $\mathrm{h}^{-1}$ (pure PVDF membranes) to $457.86 \mathrm{~L} \mathrm{~m}^{-2} \mathrm{~h}^{-1}$. Zhao et al. ${ }^{72}$ successfully synthesized a GO/copper oxide/PVDF films with improved hydrophilicity and antibacterial ability of PVDF. Peng et al. ${ }^{73}$ blended $\mathrm{r}-\mathrm{GO}$ with $\mathrm{SiO}_{2}$ and filtered the mixture on PVDF membrane. Authors reported that the novel r-GO composite film exhibits superior stability and recyclability for waste water purification.

\subsection{Comparison of GO and r-GO membranes}

The produced GO or r-GO sheets all exhibit outstanding mechanical properties because of the strong hydrogen bond in the interlayer of GO or r-GO layers. However, even though GO and r-GO have similar structure, GO membranes and r-GO membranes still have distinctions as well as similarities.

2.2.1 Laminated structure. It is a widely-known fact that GO, and r-GO membranes have a lamellar-like structure after the deposition of $2 \mathrm{D}(\mathrm{r}) \mathrm{GO}$ nanoflakes..$^{25,46,49,74}$ The structures of GO and r-GO films are shown in Fig. 6(a)-(d).

2.2.2 Pore size. A critical reason for the utilization of $\mathrm{r}-\mathrm{GO}$ membranes is that the pore size or interlayer spacing of $\mathrm{r}-\mathrm{GO}$ films is largely smaller than GO membranes, so r-GO films could be more suitable for desalination. It has been widely reported that the $d$-spacing of pure GO laminates is $\sim 0.8 \mathrm{~nm},{ }^{32,52,75,76}$ while the value for $\mathrm{r}$-GO membranes is only $\sim 0.35 \mathrm{~nm} .^{32,51,74}$ Joshi et al. ${ }^{52}$ demonstrated that GO membrane allowed the pure water to pass through but impeded solutes with hydrated diameters larger than the inter-layer spacing $(0.9 \mathrm{~nm})$ of GO membranes. However, Park et al. measured the interlayer spacing of GO powder, graphite powder, and r-GO powder. ${ }^{77}$ In this case, GO has the largest inter-sheet distance of $8.32 \AA$ among the three materials, attributed to its abundant functional groups and inserted water molecules in wet state. ${ }^{78}$ In comparison, this value for r-GO is only 3.7-3.8 A. A similar result demonstrated by Liu et $a .^{74}$ indicated that the interlayer spacing of $\mathrm{r}-\mathrm{GO}$ reduced by HI was $c a$. $3.5 \AA$, whilst that of GO is $c a$. $8.67 \AA$.

2.2.3 Permeability. GO membranes were considered as a semipermeable membrane with an extraordinary water permeate rate. In early 2012, Nair et al. ${ }^{\mathbf{4 6}}$ firstly confirmed that water can transmit through GO membranes without impediment, while blocking other vapours and gases, even the smallsized Helium (He). $\mathrm{Hu}$ and $\mathrm{Mi}^{65}$ reported that the LBL selfassembly prepared GO films exhibit a super high water flux of $276 \mathrm{LMH} / \mathrm{MPa}$. Moreover, You et al. ${ }^{54}$ demonstrated that GO films have a high constant water flux of $65 \mathrm{~L} \mathrm{~m}^{-2} \mathrm{~h}^{-1} \mathrm{bar}^{-1}$. Li et al. $^{79}$ demonstrated that a $3 \mathrm{~nm}$ GO membrane has a high water permeance of $1370 \mathrm{~L} \mathrm{~m}^{-2} \mathrm{~h}^{-1} \mathrm{bar}^{-1}$, whilst the permeance of r-GO membranes is only 0.5 to $1 \mathrm{~L} \mathrm{~m}^{-2} \mathrm{~h}^{-1} \mathrm{bar}^{-1}$. However, when the thickness of r-GO films decreases, water or other gas molecules are permeable. ${ }^{79}$ Liu et al. ${ }^{74}$ demonstrated that the water permeance of $100 \mathrm{~nm}$ thick r-GO membranes can reach to $57 \mathrm{~L} \mathrm{~m}^{-2} \mathrm{~h}^{-1}$ bar $^{-1}$. Therefore, compared to r-GO membranes, GO membranes could be more effective for the separation of large size species from water because of GO membranes' higher water permeability.

Theoretically, one-atom-layer materials with highly dense pores show high water flux rate and ions selectivity. Suk and his co-workers demonstrated that pure water could continuously flow through graphene pores with diameters smaller than $1 \mathrm{~nm}$ by molecular dynamics simulation. ${ }^{\mathbf{8 0}-82}$ With this same computational method, a research carried out by Cohen-Tanugi and Grossman $^{82}$ showed that the single-layer graphene with defect pores was able to reject salt and the water permeability of the porous membranes could reach 2 to 3 orders of magnitude higher than that of traditional RO membranes. However, the preparation of one-layer graphene is restricted due to the lack of advanced technologies. On the contrary, pure GO and r-GO membranes, which possess a lamellar structure with nanochannels and pores, were easier to prepare via depositing micronscaled layered GO crystallites. ${ }^{13}$ Moreover, GO or r-GO can also combine with various inorganics and mix with polymers, to improve the performance of (r)GO membranes and enlarge its application in water treatment and gas purification. Tables 1 and 2 demonstrates some GO and r-GO composite membranes for water treatment and gas separation, respectively, and their improved characteristics after adding inorganics or polymers. Therefore, the following sections will review various applications and separation mechanisms of (r)GO membranes in detail, which includes waste water purification, organic solvent nanofiltration, sea water desalination and gas separation.

\section{3 ( $r$ GO-based membranes for water purification}

As a novel multifunctional material, GO-assisted membranes have emerged to deal with waste water as well as to improve 

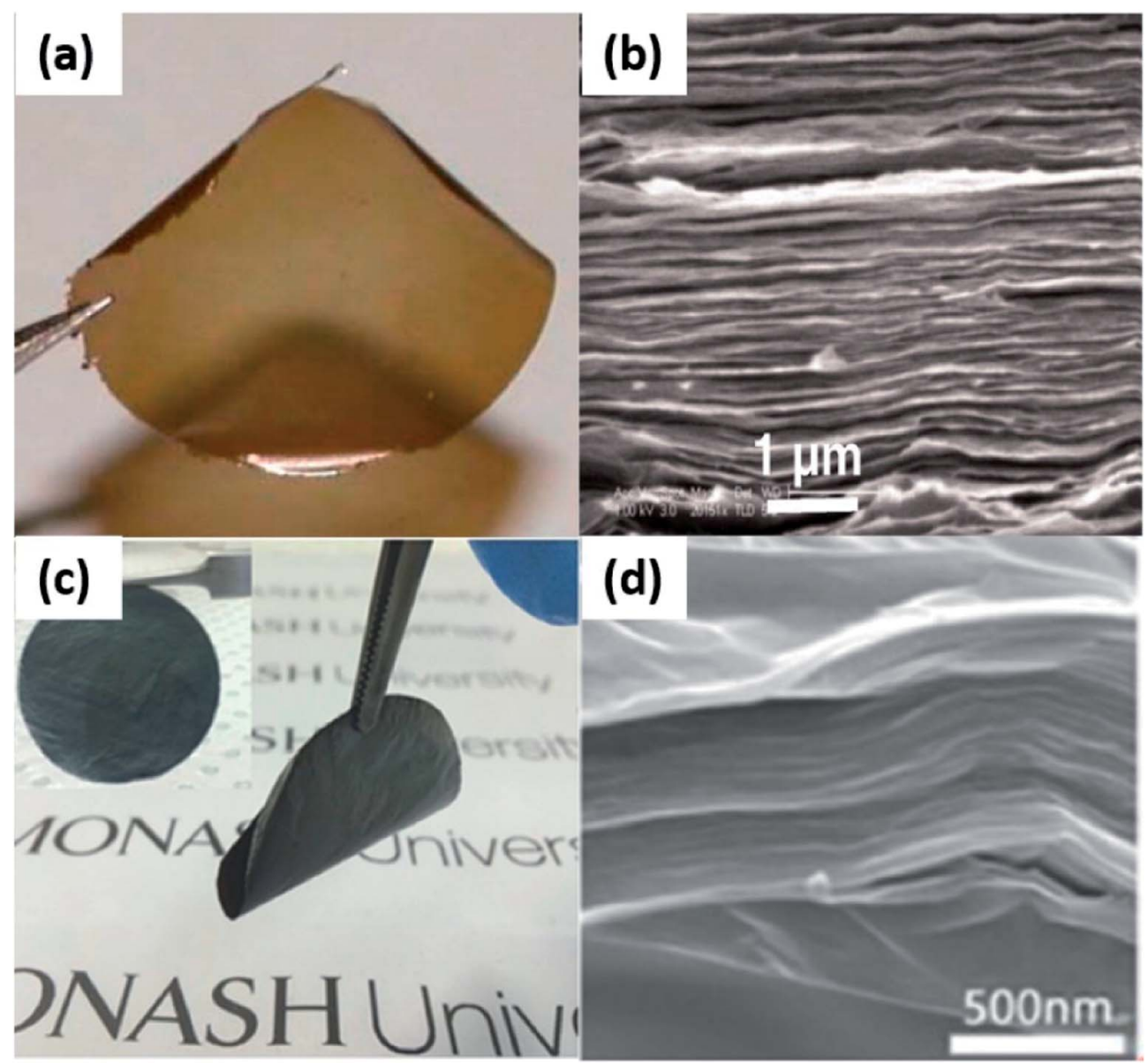

Fig. 6 (a) $1 \mu \mathrm{m}$-thick pure GO membrane; (b) the cross-section SEM image of pure laminated GO membrane; (c) $0.2 \mu \mathrm{m}$-thick r-GO membrane; (d) the cross-section SEM image of pure laminated r-GO membrane; (e) stability of pure GO laminates, $r$-GO composites membranes in neutral, acidic and alkaline solution. (a) and (b) Reproduced with permission from ref. 46. Copyright@ 2012, American Association for the Advancement of Science. (c) and (d) Reproduced with permission from ref. 74. Copyright@ 2014, John Wiley and Sons.

desalination technique. Table 2 demonstrates some recent works on water treatment with GO-assisted membranes.

\section{1 (r)GO-based membranes for waste water purification}

The waste water membrane technology aims to remove dyes, metallic ions, bacterium contaminants. Han et al..$^{55}$ used vacuum filtration method to prepare r-GO membranes in which some conventional membranes, such as PVDF, acted as substrates. The stacked r-GO films had a high water flux $\left(21.8 \mathrm{~L} \mathrm{~m}^{-2} \mathrm{~h}^{-1}\right.$ bar $)$ but the thickness remained low $(\sim 22 \mathrm{~nm})$. The rejection rate of methyl blue (MB) and direct red 81 (DR 81) using the r-GO membrane is $99.8 \%$ and $99.9 \%$, respectively. They reported that the pore size of r-GO sheets played the most important role in rejecting dyes as it is smaller than the size of dye molecules. ${ }^{55} \mathrm{Xu}$ et al ${ }^{95}$ doped $\mathrm{TiO}_{2}$ nanoparticles in GO solution to tune the size of channels and pores of lamellar $\mathrm{GO}$ sheets. They filtered $\mathrm{GO}-\mathrm{TiO}_{2}$ mixed dispersion via vacuum filtration strategy and the as-prepared $\mathrm{GO} / \mathrm{TiO}_{2}$ composite films could reject $100 \%$ of methyl orange (MO). According to blending method, Zinadini et al. ${ }^{96}$ fabricated polyethersulfone (PES)/GO hybrid membranes. In this case, GO improved the properties of bare PES, for example, the novel materials had excellent antifouling, hydrophilic ability. Furthermore, blending GO in PES could increase the pore size of prepared sheets, which may possibly increase its water flux, while the rejection rate of dyes would be reduced. Recently, Guan et al. ${ }^{97}$ combined 3D crystals (UiO-66) with 2D r-GO membranes, in which the $3 \mathrm{D}$ porous material improved the water permeability of $\mathrm{r}-\mathrm{GO}$ membranes. In this work, the pure water permeability of UiO-66rGO membranes reached to $33 \mathrm{~L} \mathrm{~m}^{-2} \mathrm{~h}^{-1} \mathrm{bar}^{-1}$ and the dye rejection was $c a .89 \%$. Zhang et al..$^{98}$ deposited various nanoparticles@rGO mixtures including $\mathrm{Fe}_{3} \mathrm{O}_{4} @ \mathrm{rGO}$, UiO-66@rGO, and $\mathrm{TiO}_{2} @ \mathrm{rGO}$ on inner surface of ceramic tubes. The authors demonstrated that these prepared NPs@rGO displayed a super high water permeance of $\sim 300 \mathrm{~L} \mathrm{~m}^{-2} \mathrm{~h}^{-1} \mathrm{bar}^{-1}$ because NPs enlarge the interlayer spacing, and a high dyes and ions rejection.

Sun et al. ${ }^{99}$ synthesized GO membranes via simple dropcoating method where they studied the separation process of ions via the as-prepared freestanding GO film. They reported that the rejection abilities of heavy-metal ions were lower than that of non-heavy metal ions as there was a tight interaction (covalent bonds) between the oxygenated functional groups on GO sheets and heavy-metal ions. Joshi et al. ${ }^{52}$ used vacuum 
Table 1 (r)GO-inorganics (or polymers) composite membranes for water treatment

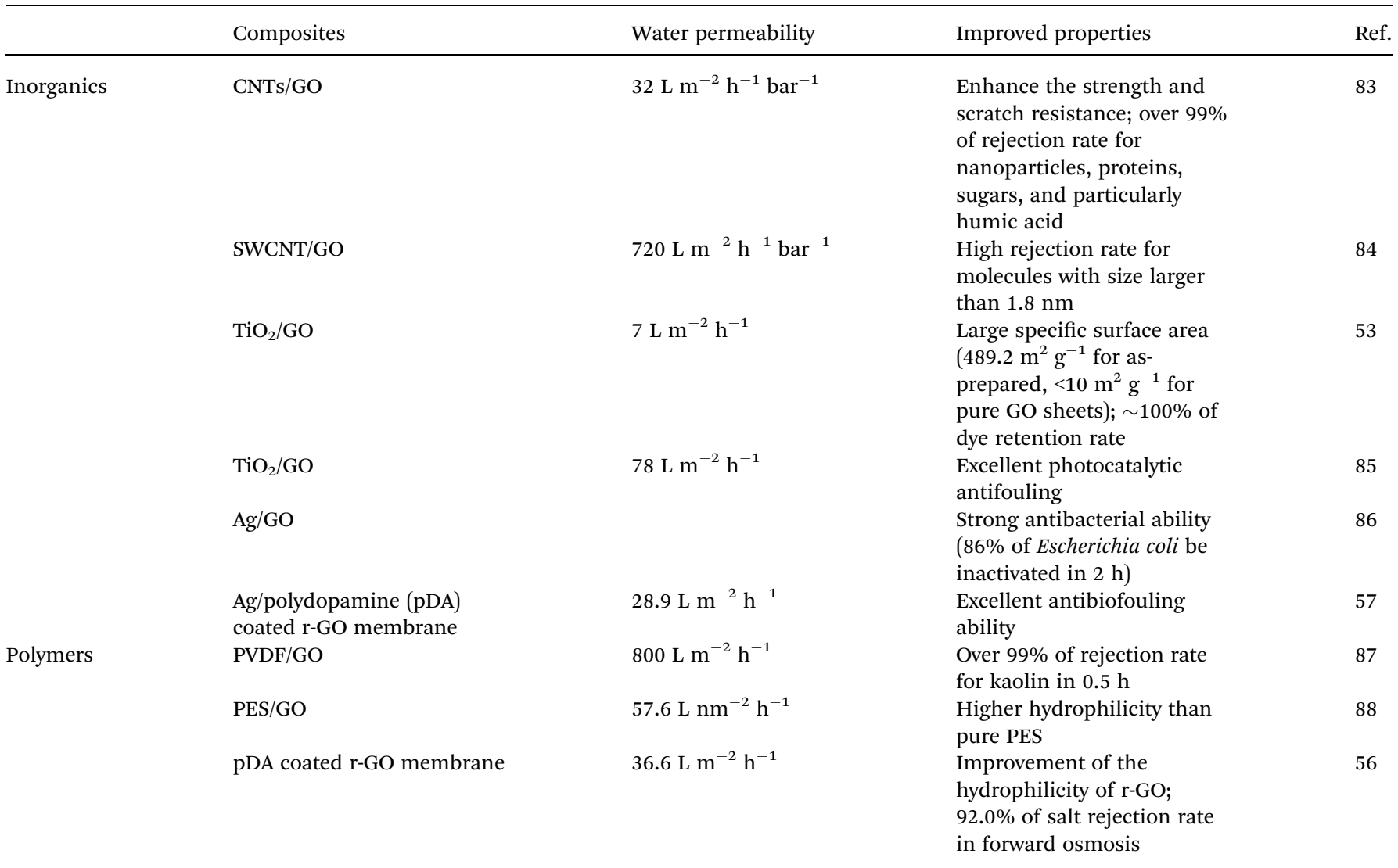

filtration method to prepare GO membranes. They reported that the permeability of GO membranes is related to ions size and the free stacking GO membranes can separate ions with diameter larger than $9 \AA$ A. Zhang et al. ${ }^{100}$ modified GO twice via crosslinking and amine-enrichment to obtain stable structure of GO membranes that were used to block ions. As a result, the novel membrane has a higher rejection rate of divalent cations than that of single valent cations because the prepared membranes are electrically neutral in solvent. As for the separation ability of GO-based membranes for ions, it is not only influenced by the pore or channel size but also related to types of ions charge (positive ions or negative ions).
In addition, the antibacterial activities of GO and r-GO are also reported. Hu et al. ${ }^{101}$ found that GO and r-GO membranes prepared by a simple vacuum filtration route have antibacterial ability which may possibly restrain the growth of Escherichia coli (E. coli). Liu et al. ${ }^{102}$ analyzed reasons for the antibacterial ability of GO and r-GO solutions. They cultivated $E$. coli cells in GO and r-GO suspensions. As a result, GO had a stronger antibacterial ability than that of r-GO because the membrane structure of GO flakes can destroy the structure of bacteria cells. Kanchanapally et $a l .{ }^{103}$ were first to utilize nisin, which is an antimicrobials agent including many $-\mathrm{NH}_{2}$ groups, to combine with GO sheets. They were successful to prepare a novel 3D porous antibacterial membrane. This as-prepared film can be used in identifying,

Table 2 (r)GO-inorganics (or - polymers) composite membranes for gas separation

\begin{tabular}{|c|c|c|c|c|}
\hline Composites & Separation & Selectivity & Improved properties & Ref. \\
\hline $\mathrm{MoS}_{2} / \mathrm{GO}$ & $\mathrm{H}_{2} / \mathrm{CO}_{2}$ & 44.2 & Higher selectivity than that of bare $\mathrm{MoS}_{2}$ membranes & 89 \\
\hline ILs/GO & $\mathrm{CO}_{2} / \mathrm{N}_{2}$ & 116 & $\begin{array}{l}\text { A stable process for the selectivity of } \mathrm{CO}_{2} / \mathrm{N}_{2} \text { and the } \\
\text { permeance of } \mathrm{CO}_{2} \text { in } 120 \mathrm{~h} \text {; easer reparation for scalable GO membrane }\end{array}$ & 90 \\
\hline Pebax/GO & $\mathrm{CO}_{2} / \mathrm{N}_{2}$ & 91 & $\begin{array}{l}\text { A smaller interlayer-spacing }(0.7 \mathrm{~nm}) \text { than that of pure } \mathrm{GO} \text { gas-separation } \\
\text { membranes in wet state }(0.79 \mathrm{~nm})\end{array}$ & 91 \\
\hline Polyimide/ZIF-8@GO & $\mathrm{CO}_{2} / \mathrm{N}_{2}$ & 65 & Improvement for the permeance of $\mathrm{CO}_{2}$ contributed by the ZIF-8 & 92 \\
\hline Pebax/r-GO & $\mathrm{CO}_{2} / \mathrm{N}_{2}$ & 104 & Enhancement for the mixed gases selectivity & 94 \\
\hline
\end{tabular}


removing and killing methicillin-resistant Staphylococcus aureus (MRSA). Recently, Yi et al. ${ }^{54}$ prepared pure freestanding GO membrane by vacuum filtration to isolate natural organic matter (NOM) from raw water. On the one hand, the fabricated GO membranes carried out a high constant NOMs water flux $\left(\sim 65 \mathrm{~L} \mathrm{~m}^{-2} \mathrm{~h}^{-1} \mathrm{bar}^{-1}\right.$ for the first $\left.6 \mathrm{~h}\right)$. On the other hand, they confirmed that bare laminated GO membranes can reject $c a$. $100 \%$ of NOMs. The results are shown in Fig. 7.

\section{2 (r)GO-based membranes for organic solvent dehydration}

According to Nair et al., ${ }^{46}$ GO membranes not only can block gases but also can resist the passage of organic vapours. In recent, therefore, many works are focusing on organic solvent nanofiltration through a pervaporation process. In pervaporation, the feed side which is a liquid mixture in contact with one side of a membrane and the permeation vapor can be removed from the other side of the membrane. ${ }^{104}$ Due to the different affinities and diffusivities in a film, the components of the mixture feed liquid can be separated. ${ }^{\mathbf{1 0 5}}$

Huang et al. ${ }^{\mathbf{1 0 6}}$ exhibited that GO membranes supported on a ceramic hollow fiber have a high water permeate rate for water-dimethyl carbonate solutions using pervaporation, in which the water content ranged from $2.6 \mathrm{wt} \%$ (feed side) to 95.2 wt\% (permeate side). Later, Huang and co-workers ${ }^{107}$ modified the GO membrane. Authors deposited a highly hydrophilic polymer, $N$-deacetylated chitin (CS), onto GO laminates that have been coated on a ceramic $\alpha-\mathrm{Al}_{2} \mathrm{O}_{3}$ hollow fiber for the water $/ n$-butanol separation using pervaporation. ${ }^{\mathbf{1 0 7}}$ In this work, the hydrophilic CS leads to attract more water molecules on the surface of the prepared CS@GO membrane and reduce organic contact with the membrane. As a result, Huang et al. ${ }^{\mathbf{1 0 7}}$ obtained a high purity water permeate content of over $99.4 \%$ with a super high water flux of over $10000 \mathrm{~g} \mathrm{~m}^{-2}$ $\mathrm{h}^{-1}$. The Fig. 8(a) and (b) shows the liquid mixture separation process using the CS@GO membrane and a photo of the membrane. Different from Hung, Lecaros et al. ${ }^{\mathbf{1 0 8}}$ based on the hydrophilic property of GO rather than depositing another hydrophilic material onto GO membrane, to achieve acetic acid dehydration, in which poly(vinyl alcohol) (PVA) has been used as a cross-linker to reduce the swelling of GO films and enhance the preparation of a uniform GO membrane. As a result, the GOPVA film possessed an excellent pervaporation performance, a good water flux of $463.9 \mathrm{~g} \mathrm{~m}^{-2} \mathrm{~h}^{-1}$ and a high water permeate of $97.7 \%{ }^{108}$ Similarly, Hua et al. ${ }^{109}$ used various cross-linkers to synthesize a series of GO membranes with different d-spacings for alcohol dehydration. The authors demonstrated that the GOF membranes exhibit a high water permeation of $99.7 \mathrm{wt} \%$ as well as an outstanding pervaporation stability for a long time of 160-200 h.

Additionally, r-GO also plays an important role in organic solvent dehydration. Hung et al. ${ }^{\mathbf{1 1 0}}$ mixed chitosan (CS) into r-GO suspension and fabricated r-GO/CS membranes with an orderly stacked lamellar structure by the casting method. The $\mathrm{r}-\mathrm{GO} / \mathrm{CS}$ films can obtain $96 \mathrm{wt} \%$ of water in permeate side. Meanwhile, the r-GO composite membranes can be produced on a large scale which is beneficial for the industrial application, and the Fig. 8(c) and (d) illustrate two sizes of r-GO/CS membranes.

\section{3 (r)GO-based membranes for desalination}

Desalination is a promising technique to solve the fresh water scarcity issue based on isolating pure water from sea water. Recently, graphene-based membranes as a series of versatile materials were studied to improve the seawater desalination technique. ${ }^{\mathbf{8 2 , 1 1 1 , 1 1 2}}$ Reverse osmosis (RO) was emerged as the greatest desalination technology, which displays a high salt rejection under a certain pressure condition. ${ }^{113}$ Furthermore, considering that RO is an energy-consuming process, many researchers are also interested in the forward osmosis (FO) technology for desalination. The main benefits of FO technique are low operation pressure, high rejection for various precises, and low membrane fouling problem. ${ }^{\mathbf{1 1 4 , 1 1 5}}$

Nicolaï et al. ${ }^{116}$ utilized MD simulation method to demonstrate that freestanding GO membranes are possible to reject salt with $100 \%$ rejection rate in RO process. For experimental results, on the one hand, modifying conventional membranes by doping (r)GO-based materials is a widely used strategy for desalination. For example, Fathizadeh and co-workers ${ }^{\mathbf{1 1 7}}$
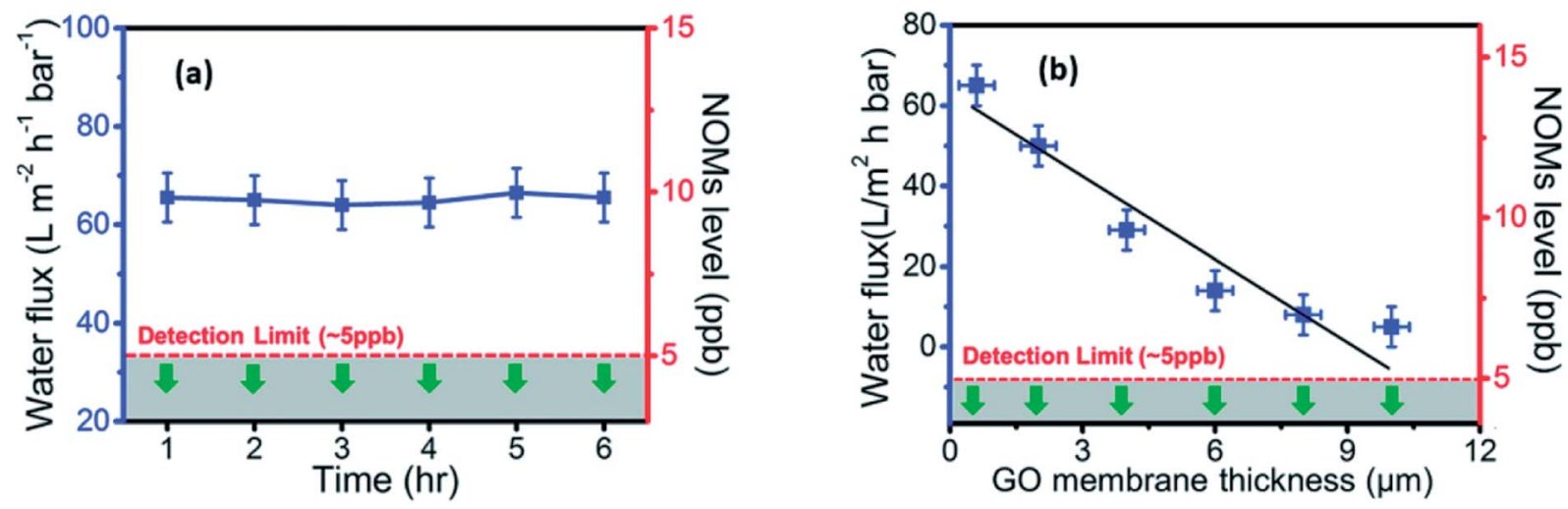

Fig. 7 (a): The blue line is the relationship between the penetration time and NOMs water flux of GO membranes $(<1 \mu \mathrm{m}$ thickness), green arrows illustrate the NOMs contents in permeate side lower than detection limit in the first $6 \mathrm{~h}$; (b) the relationship of GO membranes thickness with the NOMs water flux and NOMs contents in permeate side. Reproduced with permission from ref. 54. Copyright@ 2017 Elsevier Ltd. 


\section{(a) Feed: $\leq 10 \%$ water}

incorporated polyamide membranes with $0.02 \mathrm{wt} . / \mathrm{v} \%$ nitrogenmodified GO (N-GOQD) to prepare a novel thin RO film that showed a high salt rejection rate of $c a .93 \%$. Meanwhile, the water flux increased when the N-GOQD content grows from 0 to $0.02 \mathrm{wt} / \mathrm{v} \%$. Shi et al. ${ }^{118}$ doped small content of GO into cellulose acetate (CA). They prepared GO/CA composite membranes in which the water flux of the material improved by $129 \%$, which is higher than that of bare CA. Feng et al. ${ }^{119}$ prepared GO/ polyimide membrane via phase inversion process. These membranes displayed a high salt exclusion rate (99.9\%) and water flux $\left(36.1 \mathrm{~kg} \mathrm{~m}^{-2} \mathrm{~h}^{-1}\right)$. Depending on LBL assembled method, Kim et al. ${ }^{120}$ produced aPES/GO/aminated GO nanocomposite membranes, and authors found that the prepared GO composite membrane shows an excellent salt rejection of 98.4\% compared to the pure aPES membrane $(94.3 \%)$ using a $32000 \mathrm{ppm} \mathrm{NaCl}$ solution in feed side. In this work, Kim and co-workers $^{120}$ also found the water flux of the aPES/GO/aGO membrane is relatively low in a reverse osmosis (RO) process because of the existence of nanoparticle and sulfonated poly material. Recently, depending on the interfacial polymerization route, Li's group ${ }^{121}$ synthesized polyamide (PA)-GO hybrid reverse osmosis membranes with high $\mathrm{NaCl}$ rejection (>99.7\%), good antifouling and long-term stability. Authors stated that the d-spacing of GO membranes was declined because the oxygencarrying groups of GO reacted in the polymerization process as well. Also, the polymerization reaction enhanced the stability of GO membranes. Qian et al. ${ }^{122}$ applied pervaporation technique which is another promising method to separate salt from highsalinity water using chitosan (CS)/graphene oxide MMMs and the authors illustrated that the diffusivity of salt in the CS/GO MMM is lower than water molecules, leading to a high salt rejection of $99.9 \%$. Additionally, there are some publications on r-GO composite membranes for desalination. Safarpour et al. ${ }^{123}$ inserted $0.02 \mathrm{wt} \%$ of $\mathrm{r}-\mathrm{GO} / \mathrm{TiO}_{2}$ nanocomposite into $\mathrm{MPD} / \mathrm{TMC}$ polyamide membranes to improve the $\mathrm{NaCl}$ rejection of bare MPD/TMC polyamide membranes.

On the other hand, many researchers are devoted to preparing r-GO laminates for the rejection of $\mathrm{Na}^{+}$and $\mathrm{Cl}^{-}$ions. Abraham et $a .^{20}$ studied the effect of channel size between GO laminates on ions exclusion. They synthesized GO/r-GO 
composites for minimising the swelling of membranes and controlling the channel size in diameter of $c a .0 .4 \mathrm{~nm}$ and the produced membrane offers a high salt rejection rate of $97 \% .^{20}$ Based on the property of a narrow d-spacing of r-GO membranes, Jia and co-workers ${ }^{\mathbf{1 2 4}}$ prepared r-GO films with two reduction steps for salt rejection. The first step was using iron powder that is a mild and "green" reductant and the second step applied hydrazine. In order to obtain r-GO suspension, Jia et al. ${ }^{124}$ added sulphonation after the first step to introduce the negatively charged $\mathrm{SO}_{3}{ }^{-}$in $\mathrm{r}-\mathrm{GO}$ flakes and avoid an aggregation phenomenon, and the produced r-GO laminates by vacuum filtration displayed a high removal rate for $\mathrm{NaCl}(83.4 \%)$. Furthermore, Liu et al. ${ }^{74}$ successfully synthesized r-GO laminates by chemical reducing GO membranes and the authors reported that the interlayer spacing of the prepared r-GO sheets is merely $0.35 \mathrm{~nm}$ which exhibit a low $\mathrm{Na}^{+}$permeation of $\sim 0.2 \mathrm{~mol} \mathrm{~h}^{-1} \mathrm{~m}^{-2}$. Yang et al. ${ }^{56}$ partly reduced GO to prepare r-GO membranes with small interlayer spacing $(0.345$ $\mathrm{nm})$. Then, polydopamine, a hydrophilic material was coated on r-GO sheets for enhancing the hydrophilic ability. After FO experiments of the prepared membrane, pDA-rGO membrane has an excellent water flux $\left(36.6 \mathrm{~L} \mathrm{~m}^{-2} \mathrm{~h}^{-1}\right)$ and a high salt rejection rate $(92 \%)$ (Table 3$)$.

\section{GO and r-GO membranes for gas separation}

In addition to water purification, gas separation is another promising application for GO-based membranes. In the study of the water and gases transport for tight GO membranes, Nair demonstrated that $\mathrm{He}$ gas could be blocked by these membranes. ${ }^{46}$ However, with the regulation of related humidity and pore sizes of GO films, gases can be allowed to flow into the GO-based membranes. ${ }^{\mathbf{4 1}}$

For gas separation, there are two important parameters to define the performance of a membrane. One is the gas permeance rate or permeability which is the speed of target gases travelling through a membrane, and the other is gas selectivity which is the extent for the desired gases separating from the mixture gases. Kim et al. ${ }^{\mathbf{4 1}}$ experimentally confirmed that GObased membranes are able to be utilized into gas separation. They synthesized bare GO membranes by two methods. One was coating several laminates of GO to obtain less tight films, while the other method is spin-coating which offered super interlocked membranes. As a result (shown in Fig. 9), they found that the gas permeance through GO membranes was influenced by the water content in membranes. There was a higher gas permeance in a dry state than that in a wet environment. For the GO membranes fabricated by method one, their gas transport performance depended on the molecular weight of the gases. The other highly interlocked GO sheets exhibited a remarkable permeability for $\mathrm{CO}_{2}$ and the order for the penetration of various gases was $\mathrm{CO}_{2}>\mathrm{H}_{2} \geq \mathrm{He}>\mathrm{CH}_{4}>\mathrm{O}_{2}>$ $\mathrm{N}_{2}$. In this case, the $\mathrm{CO}_{2}$ permeability reached a high result of ca. $8500 \mathrm{GPU}$ and the selectivity of $\mathrm{CO}_{2} / \mathrm{N}_{2}$ mixtures for GO membranes prepared by the second method was approximately 20.

Li et $a .^{79}$ fabricated GO membranes with different thicknesses by the vacuum filtration method. They reported that the permeant trend of various gases through laminated GO membrane with a ca. $18 \mathrm{~nm}$ thickness was $\mathrm{H}_{2}>\mathrm{He}>\mathrm{CH}_{4}>\mathrm{CO}>$ $\mathrm{O}_{2}>\mathrm{N}_{2}>\mathrm{CO}_{2}$. Meanwhile, they obtained a super high permeance for $\mathrm{H}_{2}$ and $\mathrm{He}$ to pass through a $1.8 \mathrm{~nm}$ thickness GO membrane with ca. $1000 \times 10^{-10} \mathrm{~mol}\left(\mathrm{~m}^{2} \mathrm{~s} \mathrm{~Pa}\right)^{-1} \cdot{ }^{79}$ Surprisingly, the as-prepared GO membranes also showed an excellent selectivity for $50: 50 \mathrm{H}_{2} / \mathrm{CO}_{2}$, which was over 2000 at room temperature. The selectivity for $\mathrm{H}_{2} / \mathrm{N}_{2}$ using GO membranes with different thicknesses was higher than that of commercial membranes. In addition, they found that with the increase of GO membranes' thickness from $1.8 \mathrm{~nm}$ to $180 \mathrm{~nm}$ the permeance of $\mathrm{H}_{2}$ and $\mathrm{N}_{2}$ would decrease. ${ }^{79}$ The results are demonstrated in Fig. 10. Shen et al. ${ }^{93}$ coupled PEI with GO to synthesize GO composite membrane by LBL self-assembly. Due to the intercalation of PEI molecules, the interlayer-spacing of $\mathrm{GO} / \mathrm{PEI}$ hybrid film $(0.76 \mathrm{~nm})$ is slightly higher than that of pure GO sheet $(0.72 \mathrm{~nm})$. In this case, as-prepared membranes exhibited a super high selectivity of $\mathrm{H}_{2} / \mathrm{CO}_{2}$ and $\mathrm{H}_{2} / \mathrm{C}_{3} \mathrm{H}_{4}$, which

Table 3 Summary of recent research on water treatment with (r)GO-assisted membranes

\begin{tabular}{|c|c|c|c|c|c|c|}
\hline \multirow[t]{5}{*}{ Dye } & Methyl orange & Pure GO & Electrospraying coating & $100 \%$ & $11.13 \mathrm{~L} \mathrm{~m}^{-2} \mathrm{~h}^{-1}$ bar $^{-1}$ & 125 \\
\hline & Malachite green & $\mathrm{GO} / \mathrm{N}^{+}$-nylon & Drop coating & $98 \%$ & & 126 \\
\hline & Sunset yellow & $\mathrm{GO} / \mathrm{PFS} /$ pore former & Casting & $62.3 \%$ & $245 \mathrm{~L} \mathrm{~m}^{-2} \mathrm{~h}^{-1}$ bar $^{-1}$ & 128 \\
\hline & Methyl blue & GO/oxidized CNTs & LBL self-assembly & $99.30 \%$ & $21.71 \mathrm{~L} \mathrm{~m}^{-2} \mathrm{~h}^{-1}$ bar $^{-1}$ & 129 \\
\hline & Direct blue 14 & PEN/GO-PDA & Coating & $99.80 \%$ & $99.7 \mathrm{~L} \mathrm{~m}^{-2} \mathrm{~h}^{-1}$ & 130 \\
\hline & $\operatorname{Cr}(\mathrm{II})$ & $\mathrm{GO} /$ chitosan/PSF/PVP & Casting & ca. $95 \%$ & $41 \mathrm{~L} \mathrm{~m}^{-2} \mathrm{~h}^{-1}$ & 133 \\
\hline & $\mathrm{Cr}(\mathrm{II})$ & PDA/RGO/HNTs & Vacuum filtration & $99.01 \%$ & $237.67 \mathrm{~L} \mathrm{~m}^{-2} \mathrm{~h}^{-1}$ & 132 \\
\hline & $\mathrm{Na}_{2} \mathrm{SO}_{4}$ & GO/CN/TiO-CNT & LBL-assembly & $67 \%$ & $16 \mathrm{~L} \mathrm{~m}^{-2} \mathrm{~h}^{-1}$ bar $^{-1}$ & 134 \\
\hline & $\mathrm{NaCl}$ & $\mathrm{Ag} / \mathrm{PDA}-\mathrm{rGO}$ & Vacuum filtration & $66 \%$ & $28.9 \mathrm{~L} \mathrm{~m}^{-2} \mathrm{~h}^{-1}$ & 57 \\
\hline \multirow[t]{2}{*}{ Others } & Bovine serum albumin & GO/quaternized PSF & & $>95 \%$ & $686.16 \mathrm{~L} \mathrm{~m}^{-2} \mathrm{~h}^{-1}$ & 135 \\
\hline & Bisphenol A & GO/CN/TiO-CNT & LBL-assembly & $82 \%$ & $16 \mathrm{~L} \mathrm{~m}^{-2} \mathrm{~h}^{-1} \operatorname{bar}^{-1}$ & 134 \\
\hline
\end{tabular}


are 6- and 11- fold higher than pristine GO membranes, respectively. Meanwhile, the GO/PEI hybrid membrane also showed excellent mechanical properties; its elasticity modules was ca. $210 \mathrm{MPa}$ while that of bare GO membrane was approximately $150 \mathrm{MPa}^{93}$

In addition, Lin and Grossman ${ }^{137}$ analysed r-GO ultra-thin films for separation with MD techniques. In this work, the authors proved that more nanopores will be created after a thermal reduction and a higher epoxy/hydroxyl ratio and higher annealing temperature can lead to the enlargement of the pore size because more $\mathrm{CO}$ or $\mathrm{CO}_{2}$ gases will be released. Meanwhile Lin et $a l .{ }^{\mathbf{1 3 7}}$ explored that the porous r-GO membrane can only allow the transmission of $\mathrm{CO}_{2}$, whilst resisting $\mathrm{CH}_{4}$. Later, Dong et al. ${ }^{94}$ synthesized $\mathrm{r}-\mathrm{GO} / \mathrm{Pebax}$ MMMs for the separation of $\mathrm{CO}_{2} / \mathrm{N}_{2}$, and they utilized the narrow gas flow channels $(\sim 0.34 \mathrm{~nm})$ of the prepared membrane to enhance the selectivity that is 104. Recently, various attempts have been made by the researchers to modify pure GO or r-GO membrane for gas separation. Therefore, Table 4 replays various recent works on the gas separation of r-GO membranes and their composite films.

\section{Filtration mechanisms using laminar-structure (r)GO membranes}

\subsection{The mechanism for water purification}

GO membranes offer a high-water permeability and remarkable selectivity. ${ }^{20,34,65}$ First of all, scientists have reported that the reason for fast water flow rate of $\mathrm{GO}$ is the existence of the pristine regions (hydrophobic areas). The theory is similar to the passage of water through smooth CNT. ${ }^{145}$ On the one hand, the larger slip length of CNT will have a higher water molecules' speed. ${ }^{146}$ Falk et al. ${ }^{147}$ predicted the graphene possesses a high slip length $(80 \mathrm{~nm})$ in theory. On the other hand, water diffusion in hydrophobic parts of GO laminates' nano-channels is similar
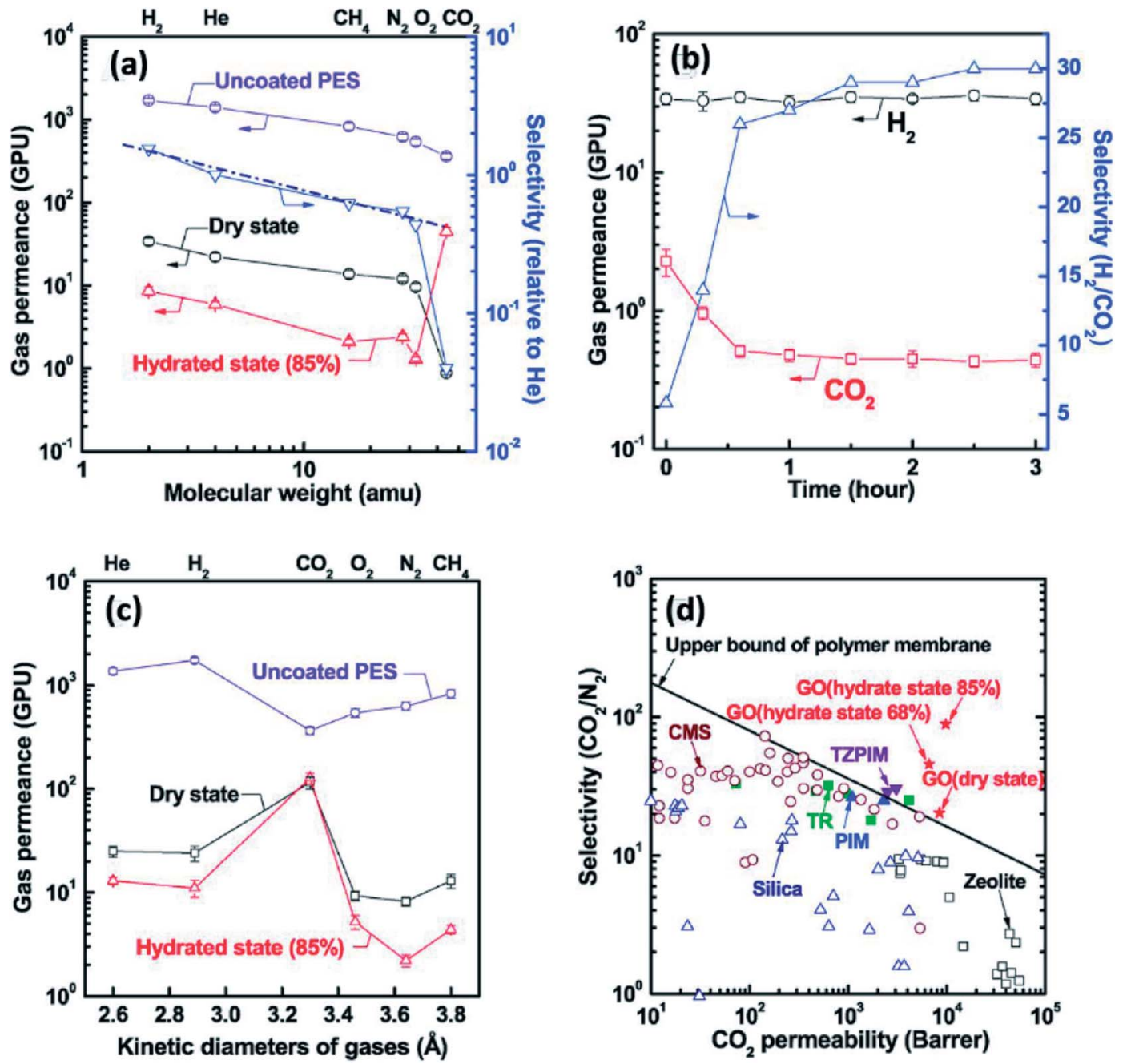

Fig. 9 (a): The impact of the environment humidity and gas molecular weight on the gas permeance performance of method one GO membranes; (b) the relation between the permeation time and $\mathrm{H}_{2}, \mathrm{CO}_{2}$ and $\mathrm{H}_{2} / \mathrm{CO}_{2}$ selectivity for method one films; (c) the impact of the environment humidity and the sizes of gases on the gas permeance performance of method two GO membranes; (d) the relationship between $\mathrm{CO}_{2}$ permeability and the $\mathrm{CO}_{2} / \mathrm{N}_{2}$ selectivity under various related humidity conditions and there is a comparison with various commercial membranes (CMS, TZPIM, TR, PIM, Zeolite and Silica). Reproduced with permission from ref. 41. Copyright@ 2013, American Association for the Advancement of Science. 

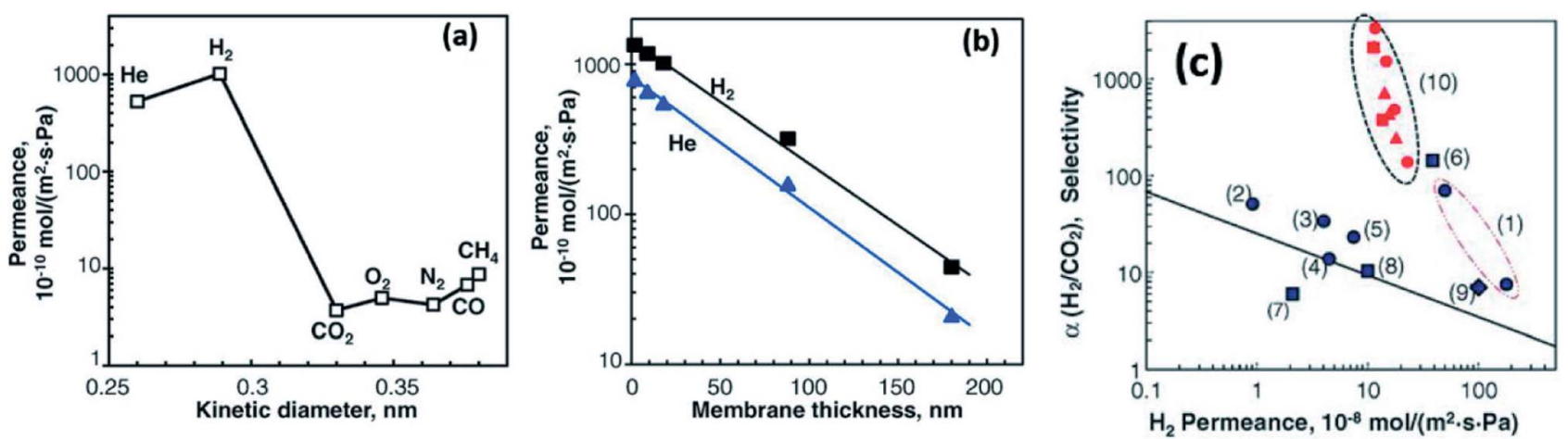

Fig. 10 (a): The permeability of GO membrane with $18 \mathrm{~nm}$ thickness for various gases of different diameters; (b): the influence of the thickness of prepared membranes on the permeance of $\mathrm{H}_{2}$ and $\mathrm{He}$; (c) the relation between $\mathrm{H}_{2}$ permeance and the selectivity of $\mathrm{H}_{2} / \mathrm{CO}_{2}$ using various commercial porous membranes and fabricated GO membranes ((1) silica, (2) silicon carbide, (3) MFI Zeolite, (4) ZIF-7, (5) zeolite composite, (6) MFI zeolite, (7) DDR zeolite, (8) silica-titania, (9) MOF, (10) GO). Reproduced with permission from ref. 79. Copyright@ 2013 , American Association for the Advancement of Science.

to the single-file diffusion type. ${ }^{148}$ It leads to the transportation mode of one-chain water molecules combined with H-bonding (the motion illustrated in Fig. 11(a)). Furthermore, water molecules in this diffusion mode can be transferred to tiny ice crystals, which cause a weak attraction between water molecules and GO pristine layers and promote the passage of water. ${ }^{149}$ Consequently, water in non-oxidized area, which is a graphenelike region, has a high pass velocity.

In addition, the structure of nanocapillaries in GO membranes contribute to the entrance of pure water into interchannels or defect pores of GO membranes. ${ }^{150} \mathrm{~A}$ strong capillary-like pressure proves that ions and molecules flow through GO channels..5 Nair et al. ${ }^{46}$ simulated the water dynamics in GO layers. Fig. 11(b) shows that there are oxidized and pristine parts in every GO sheet. They explained that the capillary-like pressure was possibly formed by pristine graphene layers, so water molecules can move faster in pristine regions than in oxidized areas. Meanwhile, the hydrogen bond between oxygen-containing functional groups and water molecules acts as the driving force for water molecules moving inside the membranes.

For the selectivity of GO membranes, Fig. 11(c) illustrates its permeation and separation mechanism. ${ }^{20,34,65}$ The nano-level defects and channels in GO films play a key role in molecules rejection. Theoretically, the interlayer spacing of GO sheets is $\sim 0.8 \mathrm{~nm}$ in a dry environment. Even though, it will be enlarged to $\sim 1.3 \mathrm{~nm}$ in an aqueous environment, it still can resist most of particles with different diameters and allow pure water molecules to pass through..$^{52}$ Therefore, GO membranes are able to deal with all sorts of water contaminants.

Additionally, thanks to the adjustable GO inter-channels, GO membranes are ideal for both waste water treatment and sea water desalination. With the decrease of nanochannels, the ions and molecules permeation rate will reduce rapidly, while it is hard to influence the water permeation. ${ }^{20} \mathrm{Mi}$ reported that when a membrane's spacing is below $0.7 \mathrm{~nm}$, it can be used in desalination because the diameter of hydrated $\mathrm{Na}^{+}$is $c a$. $0.72 \mathrm{~nm} .{ }^{21}$ When the channel size of a membrane is smaller than $2 \mathrm{~nm}$, it can only be used in waste water treatment. At the same time, various works have claimed that the inter-layer spacing of GO sheets is tunable via partly reducing GO flakes or inserting different molecules with various diameters.

Additionally, the humidity can impact GO membranes' intersheet distance because of a swelling phenomenon. Abraham et $a .^{20}$ confirmed the swelling effect clearly. Fig. 12(a) demonstrates that the interlayer spacing is increasing depending on

Table 4 Summary of recent research on gas separation with (r)GO-assisted membranes ${ }^{a}$

\begin{tabular}{|c|c|c|c|c|c|}
\hline Pure GO & Spin coating & $20 \mathrm{~nm}$ & $\mathrm{H}_{2} / \mathrm{CO}_{2}: c a .240$ & $\mathrm{H}_{2}: 3.4 \times 10^{-7} \mathrm{~mol}\left(\mathrm{~m}^{2} \mathrm{~s}^{-1} \mathrm{~Pa}\right)$ & 138 \\
\hline $\mathrm{GO} / \mathrm{K}_{2} \mathrm{~B}_{4} \mathrm{O}_{7} / \mathrm{PES}$ & Vacuum filtration & - & $\mathrm{CO}_{2} / \mathrm{CH}_{4}: 75$ & $\mathrm{CO}_{2}: 650 \mathrm{GPU}$ & 139 \\
\hline ZIF-8/GO & Contra-diffusion & $100 \mathrm{~nm}$ & $\begin{array}{l}\mathrm{H}_{2} / \mathrm{C}_{3} \mathrm{H}_{8}: 405 \\
\mathrm{H}_{2} / \mathrm{N}_{2}: 11.1\end{array}$ & $\mathrm{H}_{2}: 5.46 \times 10^{-8} \mathrm{~mol}\left(\mathrm{~m}^{2} \mathrm{~s}^{-1} \mathrm{~Pa}\right)$ & 141 \\
\hline UiO-66- $\mathrm{NH}_{2} / \mathrm{GO}$ & Vacuum filtration & $1.9 \mu \mathrm{m}$ & $\begin{array}{l}\mathrm{H}_{2} / \mathrm{N}_{2}: 9.75 \\
\mathrm{H}_{2} / \mathrm{CO}_{2}: 6.35\end{array}$ & $\mathrm{H}_{2}: 3.9 \times 10^{-8} \mathrm{~mol}\left(\mathrm{~m}^{2} \mathrm{~s}^{-1} \mathrm{~Pa}\right)$ & 142 \\
\hline Pebax/ZIF-8/GO & Casting and thermal treatment & $55-65 \mu \mathrm{m}$ & $\mathrm{CO}_{2} / \mathrm{N}_{2}: 47.6$ & $\mathrm{CO}_{2}: 249$ barrer & 144 \\
\hline Pebax/r-GO & Solution-casting & $45-60 \mu \mathrm{m}$ & $\mathrm{CO}_{2} / \mathrm{N}_{2}: 104$ & $\mathrm{CO}_{2}: 119$ barrer & 94 \\
\hline Pure GO & Spray coating & $1 \mu \mathrm{m}$ & $\mathrm{H}_{2} / \mathrm{CO}_{2}: 20.9$ & $\mathrm{H}_{2}: 2.7 \times 10^{-8} \mathrm{~mol}\left(\mathrm{~m}^{2} \mathrm{~s}^{-1} \mathrm{~Pa}\right)$ & 141 \\
\hline PEI/GO & LBL assembly & $1 \mu \mathrm{m}$ & $\mathrm{H}_{2} / \mathrm{CO}_{2}: 30$ & $\mathrm{H}_{2}: 1000$ barrer & 93 \\
\hline
\end{tabular}

${ }^{a} 1 \mathrm{GPU}=1 \times 10^{-6}(\mathrm{STP}) \mathrm{cm}^{3} /\left(\mathrm{cm}^{2} \mathrm{~s} \mathrm{cmHg}\right) ; 1$ barrer $=10^{-10} \mathrm{~cm}^{3}(\mathrm{STP}) \mathrm{cm} /\left(\mathrm{cm}^{2} \mathrm{~s} \mathrm{cmHg}\right) ; \mathrm{STP}:$ standard temperature and pressure. 
(a)

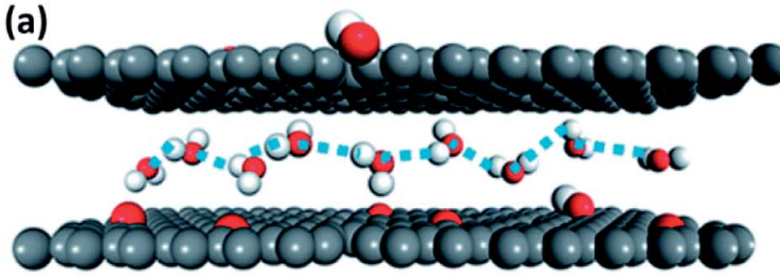

(b)

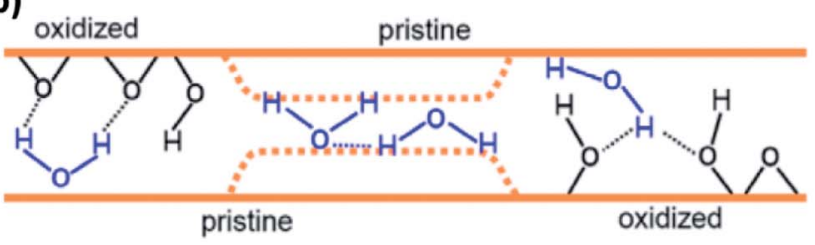

\section{(C)}
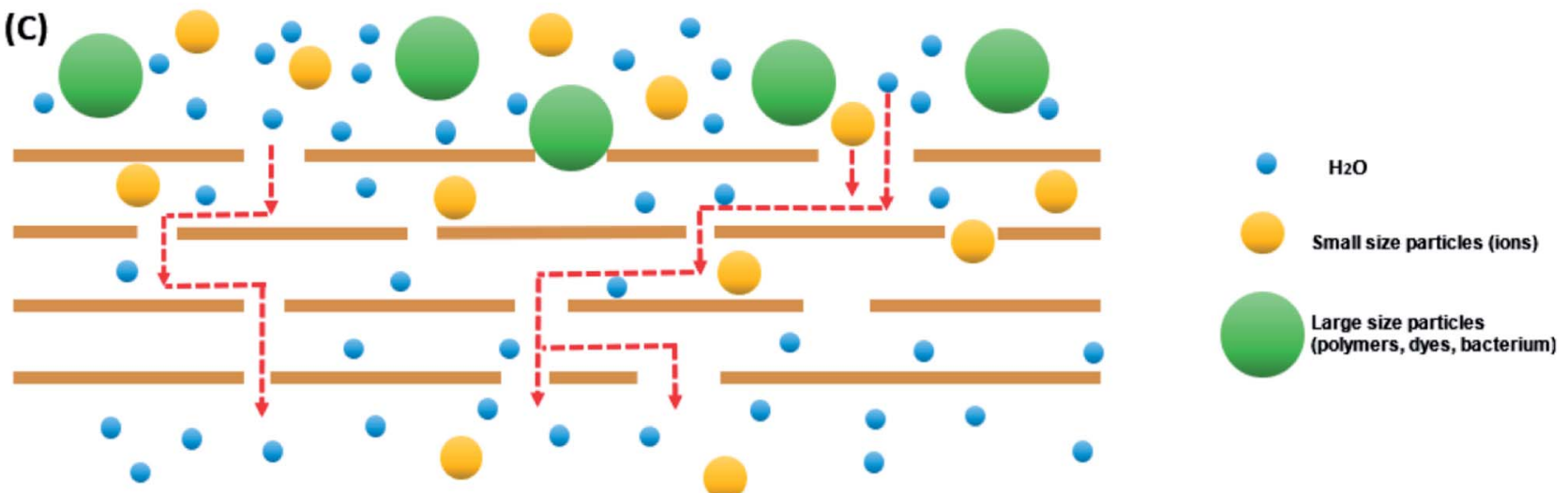

Fig. 11 (a) The schematic of monolayer water molecules in single-file type; (b) transport theories of water molecules through pristine regions and oxidized regions of GO membrane. (c) Transport process of molecules with different sizes. (a) Reproduced with permission from ref. 146, licenses address https://www.creativecommons.org/licenses/by/3.0/legalcode. (b) Reproduced with permission from ref. 46. Copyright@ 2012, American Association for the Advancement of Science.

the increase of relative humidity $(\mathrm{RH})$ of fabrication surrounding. When the $\mathrm{RH}$ is $0 \%$, GO laminates' interlayer spacing is ca. $0.64 \mathrm{~nm}$, while it is approximately $1.37 \mathrm{~nm}$ when immersed in water.

Chen et al. ${ }^{22}$ were successful to control the interlayer spacing by various cations. They compared the spacings of pure GO membranes (GOMs) immersed in DI-water and ions solutions with that of KCl-GOMs immersed in the same solutions. The result illustrates that the interlayer spacings of KCl-GOMs dropped in different salt solutions have a visible decrease. Importantly, all of the interlayer distances are almost equal to that of pure GOM immersed in KCl solution (Fig. 12(b) and (c)). Yang et $a l .{ }^{56}$ decreased GO's interlayer distance from $0.7 \mathrm{~nm}$ to $0.345 \mathrm{~nm}$ via reducing GO. At the same time, in order to keep the reduced GO membranes water permeation rate, Yang ${ }^{56}$ coated dopamine on the top of GO membranes to improve its hydrophilicity. They obtained a high salt rejection (92\%) and water flux (36.6 $\left.\mathrm{L} \mathrm{m}^{-2} \mathrm{~h}^{-1} \mathrm{bar}^{-1}\right)$.

For the pure r-GO membrane, generally the water permeation is likely lower than that of the GO laminate because the dspacing of a r-GO membrane is merely $\sim 0.35 \mathrm{~nm}$ that is too narrow to allow water, gases and other molecules transmitting through the membrane. For example, $\mathrm{Su}$ et al. ${ }^{151}$ deposited freestanding GO and r-GO films with a thickness of $\sim 0.5 \mu \mathrm{m}$ and the authors confirmed that the bare GO membrane is permeable for water while all the r-GO membranes are almost impermeable (the results are shown in Fig. 12). They explained the narrower interlayer spacing is a main reason, meanwhile $\mathrm{Su}$ et $a l .^{151}$ reported the defects created by reduction in r-GO could be the only diffusion pathway. The authors demonstrated that the interlayer spacing of three r-GO films, thermal-reduced GO film, HI-reduced GO film and CV-reduced GO film, are similar in Fig. 11. However, the thermal-reduced GO membrane can allow some water molecules transmitting rather than the other chemical-reduced GO films entirely blocking water (shown in Fig. 12(e) and (f)) because a thermal reduction process is possible to release $\mathrm{CO}$ or $\mathrm{CO}_{2}$ creating more defects. Moreover, Lin et al. ${ }^{\mathbf{1 3 7}}$ proved that a thermal reduction method is attributed to form nanopore in r-GO flakes with MD simulation.

In addition, the ultrathin r-GO membranes are able to allow the passage of water molecules which have been reported by Liu et $a .^{74}$ The authors synthesized freestanding $100 \mathrm{~nm}$ thin $\mathrm{r}-\mathrm{GO}$ membranes and the water permeability of the prepared film is $57 \mathrm{~L} \mathrm{~m}^{-2} \mathrm{~h}^{-1}$. Meanwhile, the ultrathin r-GO film displayed a high $\mathrm{Na}^{+}$rejection. Su et al. ${ }^{151}$ also obtained a high ion rejection for HI-reduced GO film. According to Liu, ${ }^{74}$ the high rejection was attributed to the narrow distance between r-GO layers and the water pathway is also the inter-channels which is same as GO laminates.

\subsection{The mechanism for gas separation}

The major conventional gas separation membranes are nonporous membranes, such as polymeric membranes, which are dependent on the solution-diffusion mechanism. ${ }^{\mathbf{1 5 2}}$ However, some porous membranes with nano-level apertures can also be used in gas separation. When the diameter of target gas is larger than the pore size, the gas would be impeded, which is considered as the molecular sieving process. ${ }^{153}$ Furthermore, when the pores are below $1 \mu \mathrm{m},{ }^{154}$ the gas transport mechanism could be regarded as the Knudsen diffusion. Knudsen diffusion for gases indicates that within a diffusion in 

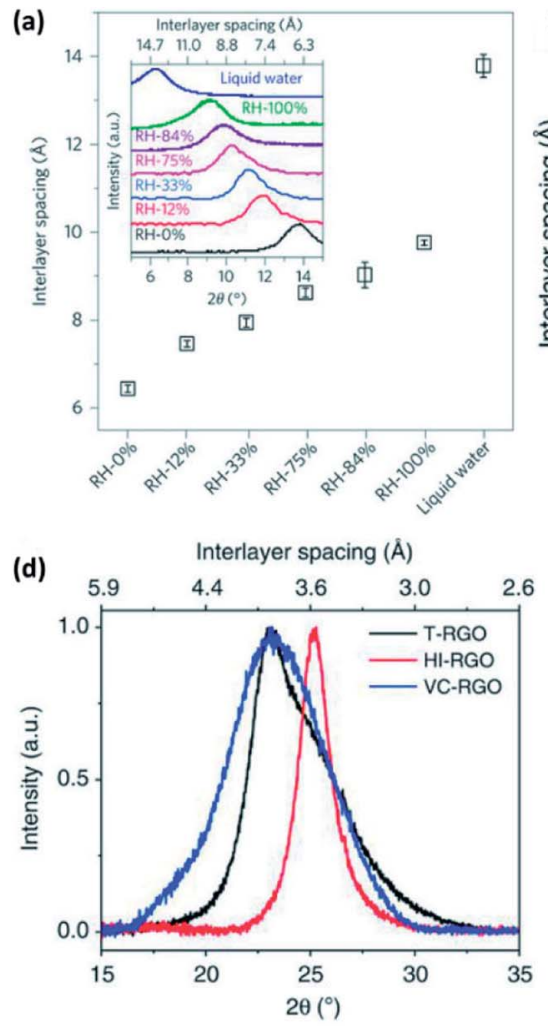

(b)

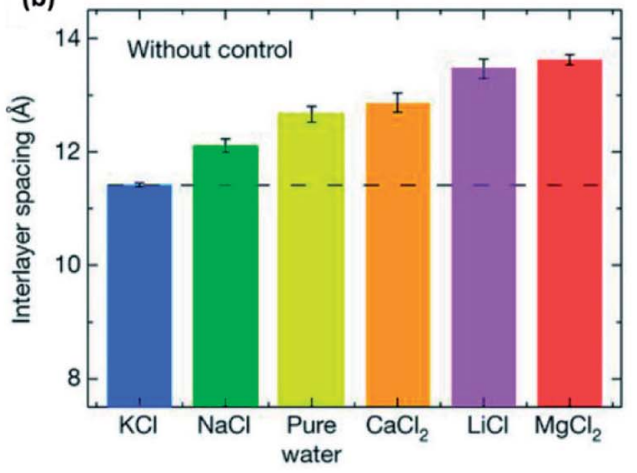

(c)

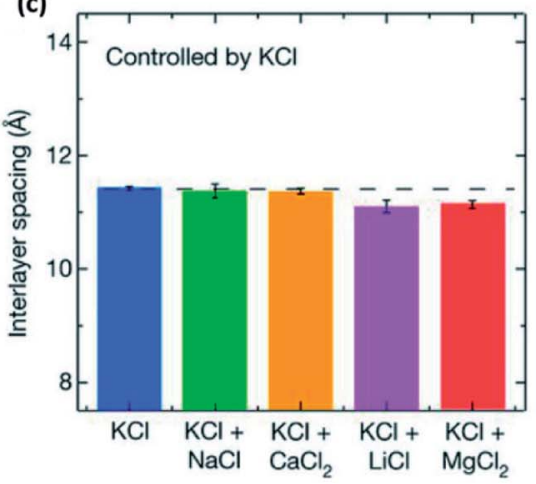

(e)

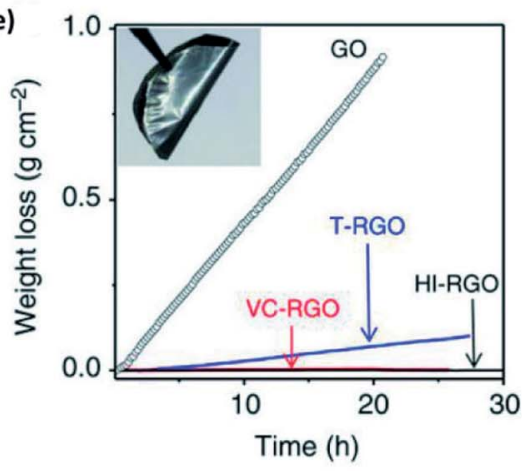

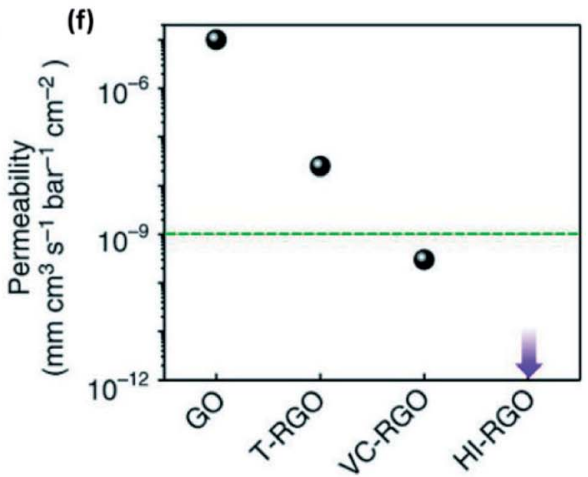

Fig. 12 (a) The influence of humidity on GO sheets' interlayer spacing, carried out by XRD (inset); (b) interlayer spacings of pure graphene oxide membranes (GOMs) after immersing in pure water and other solutions ( $\mathrm{KCl}, \mathrm{NaCl}, \mathrm{CaCl}_{2}, \mathrm{LiCl}$ and $\mathrm{MgCl}_{2}$ ); (c): Interlayer spacings of $\mathrm{GOMs}$ soaked $\mathrm{K}^{+}$after dropped in the same ions solutions; (d) the sizes of various $\mathrm{r}-\mathrm{GO}$ membranes' interlayer-spacing; (e) water loss from containers covered by GO, thermal-reduced GO, HI-reduced GO, and VC-reduced GO films; ( $f$ ) the moisture permeability of GO and various $r$-GO films. (a) Reproduced with permission from ref. 20. Copyright@ 2017, Springer Nature. (b) and (c) reproduced from ref. 22. Copyright@ 2017 , Springer Nature. (d)-(f) adapted from ref. 151. Copyright@ 2014, Springer Nature.

solid circumstance, if the pore size is equal to or smaller than the mean free path of the gases, these gas molecules are more likely to collide with the wall of the solid's pores rather than collide with each other. Thus, the resistance for gas permeance mainly depends on the collision between gas molecules and the pores wall. It is expressed as the following equation: ${ }^{93,155}$

$$
J=\frac{\Delta P}{\sqrt{2 \pi M_{\mathrm{W}} K_{\mathrm{B}} T}}
$$

where $J$ is the permeance rate through the membrane, $K_{\mathrm{B}}$ is the Boltzmann constant, $M_{\mathrm{w}}, P$ and $T$ are the molecular weight, the pressure and the temperature, respectively. Therefore, the gas permeance is inversely proportional to the square root of gas molecule weight.

Due to the porous structure of GO or r-GO films, the gas permeance mechanism could be regarded as the Knudsen transport. Guan et al. ${ }^{156}$ used pure GO membranes prepared by spray coating to investigate gas permeation and separation. They expressed that the results for $\mathrm{H}_{2}, \mathrm{CH}_{4}, \mathrm{~N}_{2}$, and $\mathrm{O}_{2}$ had a Knudsen diffusion behaviour because the molecular sizes of these tested gases are smaller than the interlayer spacing of GO sheets $(0.49 \mathrm{~nm})$. Meanwhile, authors reported that the permeance for $\mathrm{CO}_{2}$ is relatively low because of the membrane adsorption performance of $\mathrm{CO}_{2}$. Kim et al. ${ }^{41}$ prepared pure GO films by two methods (Fig. 5), in which the GO membranes fabricated by the method one exhibited a heterogeneous microstructure because of the electrostatic repulsion force between the edges of GO flakes. Authors concluded that the gases' diffusion processes obeyed the Knudsen law except $\mathrm{CO}_{2}$. With the increase of molecular weight, the gas permeances for various gases with different molecular weight were decreasing. Moreover, they explained that GO membranes would absorb $\mathrm{CO}_{2}$ because of the attraction force between $\mathrm{CO}_{2}$ and carboxyl or hydroxyl on r-GO flakes, which has also been reported by other research. ${ }^{52,54,119,157}$ The results from Kim are demonstrated in Fig. 9(a).

Besides the inversely proportional relation between the gas permeance and the gas molecular weight, Kim and his coworkers ${ }^{41}$ expressed that increasing the number of pores on GO basal planes can improve the gas permeability. In this work, the prepared r-GO membrane after a heating treatment exhibited more pores and narrower inter-channel distance than pure GO films because of the movement of oxygen-containing functionalities and the release of $\mathrm{CO}_{2}$ and $\mathrm{CO}$ from GO films. According to the Fig. $13(\mathrm{a})$, at $130{ }^{\circ} \mathrm{C}$ to $140{ }^{\circ} \mathrm{C}$ the amount of $\mathrm{CO}_{2}$ reached the peak, which created more pores on r-GO flakes and led to a rapid growth of $\mathrm{He}$ permeance. Meanwhile, there was a similar tendency of $\mathrm{H}_{2}$ permeance as $\mathrm{He}$ as a function of temperature in this case. Fig. 13(b) also shows a slight increase in the $\mathrm{CO}_{2}$ permeability at the temperatures above $140{ }^{\circ} \mathrm{C} .{ }^{41}$ 


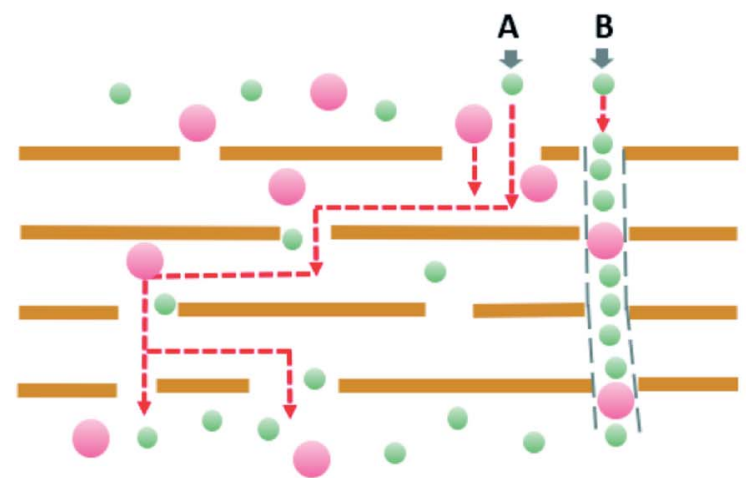

Large gas molecule: $\mathrm{CH}_{4} / \mathrm{N}_{2} / \mathrm{CO}_{2}$

Small gas molecule: $\mathrm{H}_{2} / \mathrm{He}$

Fig. 13 Two gas transport pathways in laminar GO membranes. Reproduced with permission from ref. 158. Copyright@ 2018 Elsevier B.V.

Additionally, Li et al. ${ }^{79}$ concluded that the permeation of hydrogen and helium can be reduced with the increase in the thickness of GO membranes from $1.8 \mathrm{~nm}$ to $180 \mathrm{~nm}$. The result also verified Nair's work that the He gas can be blocked by 500 nm-thick GO membranes. In this content, Li et al. ${ }^{79}$ also found that the size of the inter-layer spacing of GO membranes was not a major factor for the gas permeability unlike water filtration process where it plays an important role. Authors measured the permeance rates of various gases though GO membranes and $\mathrm{r}$ GO membranes, respectively, and they obtained similar results.

In recent, Ibrahim and $\operatorname{Lin}^{158}$ explored the mechanism of gas separation through GO laminates. Different from the previous result that $\mathrm{CO}_{2}$ permeation through $\mathrm{GO}$ membranes disobeyed Knudsen diffusion, the permeation processes for large gas molecule, such as $\mathrm{CH}_{4}, \mathrm{~N}_{2}$, and $\mathrm{CO}_{2}$, performed a Knudsen diffusion behaviour, while that for small gases $\left(\mathrm{H}_{2}\right.$ and $\left.\mathrm{He}\right)$ were higher than the gases' theoretical Knudsen permeance. The two authors explained that there were two possible pathways for gas transport in GO membranes, which are demonstrated in Fig. 13. The model A is a winding path that consists of inter-channels, defects on GO basal planes, and nano-gaps between adjacent GO flakes. The model B is an approximately straight narrow tunnel. Therefore, the overall gas permeance for a GO membrane is contributed to the two pathways. At room temperature, the major large gases transmitted through the pathway A because its diffusion activation energy $\left(E_{\mathrm{d}}\right)$ in the model A is smaller than that in the second transport road and the gas flow through passageway B can be ignored. Thus, the diffusion for large gas molecules was same as the Knudsen diffusion. However, besides a high permeability of $\mathrm{H}_{2}$ and $\mathrm{He}$ through the pathway $\mathrm{A}$, the small gases permeance through pathway B also showed a considerable value.

Compared with other uniform porous membranes, the gas separation mechanism for GO or r-GO laminates remains unclear because the actual micro-structures of r-GO membranes are different when the conditions for r-GO suspensions or the membrane synthesis method change.

\section{Conclusions}

In summary, GO has been considered as a promising membrane material for water purification and separation applications with its excellent hydrophilicity, considerable defects, pores structure, and nanosized flakes. Through some physical routes, such as spin coating, drop coating, dip coating, layer-by-layer deposition and vacuum filtration, GO flakes can be stacked uniformly to form GO membranes with laminar structure.

It is noteworthy that the nano-channels of multilayer GO sheets are controllable, which can be realized by reduction to form r-GO or reaction with polymers or nanoparticles. These modifications of GO are likely to overcome the swelling phenomenon of GO sheets in water environment. Thanks to the tunable inter-sheet distance, the laminated membranes can achieve the selection of gases and separate pollutants with different sizes from waste water, even the small hydrated sodium ions. In the future, there is no doubt that GO related membranes are favourable candidates for blocking ions and molecules. Still, further studies need to be done like the ionic/ molecular transport behaviour along the nano-channels of GO membranes and the trade-off between ionic/molecular selectivity and permeability in GO related membranes.

\section{Conflicts of interest}

There are no conflicts to declare.

\section{References}

$1 \mathrm{~W}$. J. Koros and C. Zhang, Materials for next-generation molecularly selective synthetic membranes, Nat. Mater., 2017, 16(3), 289.

2 J. Wang, J. Zhu, Y. Zhang, J. Liu and B. Van der Bruggen, Nanoscale tailor-made membranes for precise and rapid molecular sieve separation, Nanoscale, 2017, 9(9), 29422957.

3 J. R. Werber, C. O. Osuji and M. Elimelech, Materials for next-generation desalination and water purification membranes, Nat. Rev. Mater., 2016, 1, 16018.

4 G. M. Geise, H. Lee, D. J. Miller, B. D. Freeman, J. E. McGrath and D. R. Paul, Water purification by membranes: the role of polymer science, J. Polym. Sci., Part B: Polym. Phys., 2010, 48(15), 1685-1718. 
5 A. I. Schäfer, A. G. Fane and T. D. Waite. Nanofiltration: Principles and Applications, Elsevier, 2005.

6 M. Kazemimoghadam, New nanopore zeolite membranes for water treatment, Desalination, 2010, 251(1-3), 176-180.

7 M. M. Pendergast and E. M. V. Hoek, A review of water treatment membrane nanotechnologies, Energy Environ. Sci., 2011, 4(6), 1946-1971.

8 M. A. Shannon, P. W. Bohn, M. Elimelech, J. G. Georgiadis, B. J. Marinas and A. M. Mayes, Science and technology for water purification in the coming decades, Nature, 2008, 452(7185), 301.

9 Q. Xu, H. Xu, J. Chen, Y. Lv, C. Dong and T. S. Sreeprasad, Graphene and graphene oxide: advanced membranes for gas separation and water purification, Inorg. Chem. Front., 2015, 2(5), 417-424.

10 I. E. Abbott's, Graphene: Exploring carbon flatland, Phys. Today, 2007, 60(8), 35.

11 A. K. Geim and K. S. Novoselov, The rise of graphene, Nat. Mater., 2007, 6(3), 183.

12 Y. Si and E. T. Samulski, Synthesis of water soluble graphene, Nano Lett., 2008, 8(6), 1679-1682.

13 D. A. Dikin, S. Stankovich, E. J. Zimney, R. D. Piner, G. H. B. Dommett, G. Evmenenko, et al. Preparation and characterization of graphene oxide paper, Nature, 2007, 448(7152), 457.

14 H. C. Schniepp, J.-L. Li, M. J. McAllister, H. Sai, M. HerreraAlonso, D. H. Adamson, et al. Functionalized single graphene sheets derived from splitting graphite oxide, $J$. Phys. Chem. B, 2006, 110(17), 8535-8539.

15 W. S. Hummers Jr and R. E. Offeman, Preparation of graphitic oxide, J. Am. Chem. Soc., 1958, 80(6), 1339.

16 K. R. Koch, Oxidation by Mn207: an impressive demonstration of the powerful oxidizing property of dimanganeseheptoxide, J. Chem. Educ., 1982, 59(11), 973.

17 H. He, J. Klinowski, M. Forster and A. Lerf, A new structural model for graphite oxide, Chem. Phys. Lett., 1998, 287(1), $53-56$.

18 J. I. Paredes, S. Villar-Rodil, A. Martínez-Alonso and J. M. D. Tascon, Graphene oxide dispersions in organic solvents, Langmuir, 2008, 24(19), 10560-10564.

19 L. J. Cote, J. Kim, V. C. Tung, J. Luo, F. Kim and J. Huang, Graphene oxide as surfactant sheets, Pure Appl. Chem., 2010, 83(1), 95-110.

20 J. Abraham, K. S. Vasu, C. D. Williams, K. Gopinadhan, Y. Su, C. T. Cherian, et al. Tunable sieving of ions using graphene oxide membranes, Nat. Nanotechnol., 2017, 12(6), 546-550.

$21 \mathrm{~B} . \mathrm{Mi}$, Graphene oxide membranes for ionic and molecular sieving, Science, 2014, 343(6172), 740-742.

22 L. Chen, G. Shi, J. Shen, B. Peng, B. Zhang, Y. Wang, et al. Ion sieving in graphene oxide membranes via cationic control of interlayer spacing, Nature, 2017, 550(7676), 380.

23 B. Ou, Z. Zhou, Q. Liu, B. Liao, S. Yi, Y. Ou, et al. Covalent functionalization of graphene with poly (methyl methacrylate) by atom transfer radical polymerization at room temperature, Polym. Chem., 2012, 3(10), 2768-2775.
24 C. Cheng and D. Li, Solvated graphenes: an emerging class of functional soft materials, Adv. Mater., 2013, 25(1), 13-30.

25 G. Eda and M. Chhowalla, Chemically derived graphene oxide: towards large-area thin-film electronics and optoelectronics, Adv. Mater., 2010, 22(22), 2392-2415.

26 S. Pei and H.-M. Cheng, The reduction of graphene oxide, Carbon, 2012, 50(9), 3210-3228.

27 S. Park and R. S. Ruoff, Chemical methods for the production of graphenes, Nat. Nanotechnol., 2009, 4(4), 217.

28 L. Stobinski, B. Lesiak, A. Malolepszy, M. Mazurkiewicz, B. Mierzwa, J. Zemek, et al. Graphene oxide and reduced graphene oxide studied by the XRD, TEM and electron spectroscopy methods, J. Electron Spectrosc. Relat. Phenom., 2014, 195, 145-154.

29 Y. Zhu, S. Murali, M. D. Stoller, A. Velamakanni, R. D. Piner and R. S. Ruoff, Microwave assisted exfoliation and reduction of graphite oxide for ultracapacitors, Carbon, 2010, 48(7), 2118-2122.

30 S. Stankovich, D. A. Dikin, R. D. Piner, K. A. Kohlhaas, A. Kleinhammes, Y. Jia, et al. Synthesis of graphene-based nanosheets via chemical reduction of exfoliated graphite oxide, Carbon, 2007, 45(7), 1558-1565.

$31 \mathrm{M}$. Periasamy and M. Thirumalaikumar, Methods of enhancement of reactivity and selectivity of sodium borohydride for applications in organic synthesis, $J$. Organomet. Chem., 2000, 609(1-2), 137-151.

32 S. Pei, J. Zhao, J. Du, W. Ren and H.-M. Cheng, Direct reduction of graphene oxide films into highly conductive and flexible graphene films by hydrohalic acids, Carbon, 2010, 48(15), 4466-4474.

33 M. J. Fernández-Merino, L. Guardia, J. I. Paredes, S. VillarRodil, P. Solís-Fernández, A. Martínez-Alonso, et al. Vitamin $\mathrm{C}$ is an ideal substitute for hydrazine in the reduction of graphene oxide suspensions, J. Phys. Chem. C, 2010, 114(14), 6426-6432.

34 C. Zhu, S. Guo, Y. Fang and S. Dong, Reducing sugar: new functional molecules for the green synthesis of graphene nanosheets, ACS Nano, 2010, 4(4), 2429-2437.

35 Y. Wang, Z. Shi and J. Yin, Facile synthesis of soluble graphene via a green reduction of graphene oxide in tea solution and its biocomposites, ACS Appl. Mater. Interfaces, 2011, 3(4), 1127-1133.

36 Y. Zhou, Q. Bao, L. A. L. Tang, Y. Zhong and K. P. Loh, Hydrothermal dehydration for the "green" reduction of exfoliated graphene oxide to graphene and demonstration of tunable optical limiting properties, Chem. Mater., 2009, 21(13), 2950-2956.

37 Y. Xu, K. Sheng, C. Li and G. Shi, Self-assembled graphene hydrogel via a one-step hydrothermal process, ACS Nano, 2010, 4(7), 4324-4330.

38 K. Erickson, R. Erni, Z. Lee, N. Alem, W. Gannett and A. Zettl, Determination of the local chemical structure of graphene oxide and reduced graphene oxide, Adv. Mater., 2010, 22(40), 4467-4472.

39 D. Li, M. B. Müller, S. Gilje, R. B. Kaner and G. G. Wallace, Processable aqueous dispersions of graphene nanosheets, Nat. Nanotechnol., 2008, 3(2), 101. 
40 S. Park, J. An, I. Jung, R. D. Piner, S. J. An, X. Li, et al. Colloidal suspensions of highly reduced graphene oxide in a wide variety of organic solvents, Nano Lett., 2009, 9(4), 1593-1597.

41 H. W. Kim, H. W. Yoon, S.-M. Yoon, B. M. Yoo, B. K. Ahn, Y. H. Cho, et al. Selective gas transport through fewlayered graphene and graphene oxide membranes, Science, 2013, 342(6154), 91-95.

42 H. A. Becerril, J. Mao, Z. Liu, R. M. Stoltenberg, Z. Bao and Y. Chen, Evaluation of solution-processed reduced graphene oxide films as transparent conductors, ACS Nano, 2008, 2(3), 463-470.

43 D. B. Hall, P. Underhill and J. M. Torkelson, Spin coating of thin and ultrathin polymer films, Polym. Eng. Sci., 1998, 38(12), 2039-2045.

44 A. G. Emslie, F. T. Bonner and L. G. Peck, Flow of a viscous liquid on a rotating disk, J. Appl. Phys., 1958, 29(5), 858-862.

45 L. E. Scriven, Physics and applications of dip coating and spin coating, MRS Online Proc. Libr., 1988, 121, 717.

46 R. R. Nair, H. A. Wu, P. N. Jayaram, I. V. Grigorieva and A. K. Geim, Unimpeded permeation of water through helium-leak-tight graphene-based membranes, Science, 2012, 335(6067), 442-444.

47 J. Wu, H. A. Becerril, Z. Bao, Z. Liu, Y. Chen and P. Peumans, Organic solar cells with solution-processed graphene transparent electrodes, Appl. Phys. Lett., 2008, 92(26), 237.

48 H. Chang, Z. Sun, Q. Yuan, F. Ding, X. Tao, F. Yan, et al. Thin Film Field-Effect Phototransistors From BandgapTunable, Solution-Processed, Few-Layer Reduced Graphene Oxide Films, Adv. Mater., 2010, 22(43), 48724876.

49 D. A. Dikin, S. Stankovich, E. J. Zimney, R. D. Piner, G. H. B. Dommett, G. Evmenenko and R. S. Ruoff, Preparation and characterization of graphene oxide paper, Nature, 2007, 448(7152), 457-460.

50 C.-N. Yeh, K. Raidongia, J. Shao, Q.-H. Yang and J. Huang, On the origin of the stability of graphene oxide membranes in water, Nat. Chem., 2015, 7(2), 166.

51 G. Eda, G. Fanchini and M. Chhowalla, Large-area ultrathin films of reduced graphene oxide as a transparent and flexible electronic material, Nat. Nanotechnol., 2008, 3(5), 270-274.

52 R. K. Joshi, P. Carbone, F.-C. Wang, V. G. Kravets, Y. Su, I. V. Grigorieva, et al. Precise and ultrafast molecular sieving through graphene oxide membranes, Science, 2014, 343(6172), 752-754.

$53 \mathrm{C} . \mathrm{Xu}, \mathrm{A}$. Cui, Y. $\mathrm{Xu}$ and $\mathrm{X} . \mathrm{Fu}$, Graphene oxide-TiO ${ }_{2}$ composite filtration membranes and their potential application for water purification, Carbon, 2013, 62, 465471.

54 Y. You, X. H. Jin, X. Y. Wen, V. Sahajwalla, V. Chen, H. Bustamante, et al. Application of graphene oxide membranes for removal of natural organic matter from water, Carbon, 2018, 129, 415-419, DOI: 10.1016/ j.carbon.2017.12.032.
55 Y. Han, Z. Xu and C. Gao, Ultrathin graphene nanofiltration membrane for water purification, Adv. Funct. Mater., 2013, 23(29), 3693-3700.

56 E. Yang, C.-M. Kim, J. Song, H. Ki, M.-H. Ham and I. S. Kim, Enhanced desalination performance of forward osmosis membranes based on reduced graphene oxide laminates coated with hydrophilic polydopamine, Carbon, 2017, 117, 293-300.

57 E. Yang, A. B. Alayande, C.-M. Kim, J. Song and I. S. Kim, Laminar reduced graphene oxide membrane modified with silver nanoparticle-polydopamine for water/ion separation and biofouling resistance enhancement, Desalination, 2018, 426, 21-31.

58 H. Zhang, X. Quan, S. Chen, X. Fan, G. Wei and H. Yu, Combined Effects of Surface Charge and Pore Size on CoEnhanced Permeability and Ion Selectivity Through RGOOCNT Nanofiltration Membranes, Environ. Sci. Technol., 2018, 52(8), 4827-4834.

59 K. H. Thebo, X. Qian, Q. Zhang, L. Chen, H.-M. Cheng and W. Ren, Highly stable graphene-oxide-based membranes with superior permeability, Nat. Commun., 2018, 9(1), 1486.

60 H. Bai, C. Li, X. Wang and G. Shi, A pH-sensitive graphene oxide composite hydrogel, Chem. Commun., 2010, 46(14), 2376-2378.

61 T. Szabó, O. Berkesi, P. Forgó, K. Josepovits, Y. Sanakis, D. Petridis, et al. Evolution of surface functional groups in a series of progressively oxidized graphite oxides, Chem. Mater., 2006, 18(11), 2740-2749.

62 L. Yu, Y.-S. Lim, J. H. Han, K. Kim, J. Y. Kim, S.-Y. Choi, et al. A graphene oxide oxygen barrier film deposited via a selfassembly coating method, Synth. Met., 2012, 162(7), 710714.

$63 \mathrm{D}$. $\mathrm{Yu}$ and L. Dai, Self-assembled graphene/carbon nanotube hybrid films for supercapacitors, J. Phys. Chem. Lett., 2009, 1(2), 467-470.

64 D. W. Lee, T.-K. Hong, D. Kang, J. Lee, M. Heo, J. Y. Kim, et al. Highly controllable transparent and conducting thin films using layer-by-layer assembly of oppositely charged reduced graphene oxides, J. Mater. Chem., 2011, 21(10), 3438-3442.

65 M. Hu and B. Mi, Enabling Graphene Oxide Nanosheets as Water Separation Membranes, Environ. Sci. Technol., 2013, 47(8), 3715-3723.

66 L. J. Cote, J. Kim, Z. Zhang, C. Sun and J. Huang, Tunable assembly of graphene oxide surfactant sheets: wrinkles, overlaps and impacts on thin film properties, Soft Matter, 2010, 6(24), 6096-6101.

67 J. Shen, Y. Hu, C. Li, C. Qin, M. Shi and M. Ye, Layer-by-layer self-assembly of graphene nanoplatelets, Langmuir, 2009, 25(11), 6122-6128.

68 M. Krueger, S. Berg, D. Stone, E. Strelcov, D. A. Dikin, J. Kim, et al. Drop-casted self-assembling graphene oxide membranes for scanning electron microscopy on wet and dense gaseous samples, ACS Nano, 2011, 5(12), 1004710054. 
69 S. Gilje, S. Han, M. Wang, K. L. Wang and R. B. Kaner, A chemical route to graphene for device applications, Nano Lett., 2007, 7(11), 3394-3398.

70 C. J. Brinker, G. C. Frye, A. J. Hurd and C. S. Ashley, Fundamentals of sol-gel dip coating, Thin Solid Films, 1991, 201(1), 97-108.

71 Z. Wang, H. Yu, J. Xia, F. Zhang, F. Li, Y. Xia, et al. Novel GOblended PVDF ultrafiltration membranes, Desalination, 2012, 299, 50-54.

72 C. Zhao, J. Lv, X. Xu, G. Zhang, Y. Yang and F. Yang, Highly antifouling and antibacterial performance of poly(vinylidene fluoride) ultrafiltration membranes blending with copper oxide and graphene oxide nanofillers for effective wastewater treatment, $J$. Colloid Interface Sci., 2017, 505, 341-351.

73 Y. Peng, Z. Yu, F. Li, Q. Chen, D. Yin and X. Min, A novel reduced graphene oxide-based composite membrane prepared via a facile deposition method for multifunctional applications: oil/water separation and cationic dyes removal, Sep. Purif. Technol., 2018, 200, 130140.

$74 \mathrm{H}$. Liu, H. Wang and X. Zhang, Facile fabrication of freestanding ultrathin reduced graphene oxide membranes for water purification, Adv. Mater., 2015, 27(2), 249-254.

75 A. Lerf, A. Buchsteiner, J. Pieper, S. Schöttl, I. Dekany, T. Szabo, et al. Hydration behavior and dynamics of water molecules in graphite oxide, J. Phys. Chem. Solids, 2006, 67(5-6), 1106-1110.

76 D. W. Boukhvalov, M. I. Katsnelson and Y.-W. Son, Origin of anomalous water permeation through graphene oxide membrane, Nano Lett., 2013, 13(8), 3930-3935.

77 S. Park, J. An, J. R. Potts, A. Velamakanni, S. Murali and R. S. Ruoff, Hydrazine-reduction of graphite- and graphene oxide, Carbon, 2011, 49(9), 3019-3023.

78 A. Buchsteiner, A. Lerf and J. Pieper, Water dynamics in graphite oxide investigated with neutron scattering, $J$. Phys. Chem. B, 2006, 110(45), 22328-22338.

79 H. Li, Z. Song, X. Zhang, Y. Huang, S. Li, Y. Mao, et al. Ultrathin, molecular-sieving graphene oxide membranes for selective hydrogen separation, Science, 2013, 342(6154), 95-98.

80 M. E. Suk and N. R. Aluru, Water transport through ultrathin graphene, J. Phys. Chem. Lett., 2010, 1(10), 15901594.

81 M. Elimelech and W. A. Phillip, The future of seawater desalination: energy, technology, and the environment, Science, 2011, 333(6043), 712-717.

82 D. Cohen-Tanugi and J. C. Grossman, Water desalination across nanoporous graphene, Nano Lett., 2012, 12(7), 3602-3608.

83 X. Chen, M. Qiu, H. Ding, K. Fu and Y. Fan, A reduced graphene oxide nanofiltration membrane intercalated by well-dispersed carbon nanotubes for drinking water purification, Nanoscale, 2016, 8(10), 5696-5705.
84 S. J. Gao, H. Qin, P. Liu and J. Jin, SWCNT-intercalated GO ultrathin films for ultrafast separation of molecules, $J$. Mater. Chem. A, 2015, 3(12), 6649-6654.

85 C. Xu, Y. Xu and J. Zhu, Photocatalytic antifouling graphene oxide-mediated hierarchical filtration membranes with potential applications on water purification, ACS Appl. Mater. Interfaces, 2014, 6(18), 16117-16123.

86 X.-F. Sun, J. Qin, P.-F. Xia, B.-B. Guo, C.-M. Yang, C. Song, et al. Graphene oxide-silver nanoparticle membrane for biofouling control and water purification, Chem. Eng. J., 2015, 281, 53-59.

87 W. Janga, J. Yuna, K. Jeonb and H. Byuna, PVdF/graphene oxide hybrid membrane via electrospinning for water treatment application, Inorg. Mater., 2015, 9, 10.

88 S. A. Kiran, Y. L. Thuyavan, G. Arthanareeswaran, T. Matsuura and A. F. Ismail, Impact of graphene oxide embedded polyethersulfone membranes for the effective treatment of distillery effluent, Chem. Eng. J., 2016, 286, 528-537.

89 M. Ostwal, D. B. Shinde, X. Wang, I. Gadwal and Z. Lai, Graphene oxide-molybdenum disulfide hybrid membranes for hydrogen separation, J. Membr. Sci., 2017, 550, 145-154.

90 M. Karunakaran, L. F. Villalobos, M. Kumar, R. Shevate, F. H. Akhtar and K.-V. Peinemann, Graphene oxide doped ionic liquid ultrathin composite membranes for efficient $\mathrm{CO}_{2}$ capture, J. Mater. Chem. A, 2017, 5(2), 649-656.

91 J. Shen, G. Liu, K. Huang, W. Jin, K. Lee and N. Xu, Membranes with fast and selective gas-transport channels of laminar graphene oxide for efficient $\mathrm{CO}_{2}$ capture, Angew. Chem., 2015, 127(2), 588-592.

92 D. Huang, Q. Xin, Y. Ni, Y. Shuai, S. Wang, Y. Li, et al. Synergistic effects of zeolite imidazole framework@ graphene oxide composites in humidified mixed matrix membranes on $\mathrm{CO}_{2}$ separation, $R S C A d v$., 2018, 8(11), 6099-6109.

93 J. Shen, G. Liu, K. Huang, Z. Chu, W. Jin and N. Xu, Subnanometer two-dimensional graphene oxide channels for ultrafast gas sieving, ACS Nano, 2016, 10(3), 3398-3409.

94 G. Dong, J. Hou, J. Wang, Y. Zhang, V. Chen and J. Liu, Enhanced $\mathrm{CO}_{2} / \mathrm{N}_{2}$ separation by porous reduced graphene oxide/Pebax mixed matrix membranes, J. Membr. Sci., 2016, 520, 860-868.

$95 \mathrm{C} . \mathrm{Xu}, \mathrm{A} . \mathrm{Cui}, \mathrm{Y} . \mathrm{Xu}$ and X. Fu, Graphene oxide- $\mathrm{TiO}_{2}$ composite filtration membranes and their potential application for water purification, Carbon, 2013, 62, 465471.

96 S. Zinadini, A. A. Zinatizadeh, M. Rahimi, V. Vatanpour and H. Zangeneh, Preparation of a novel antifouling mixed matrix PES membrane by embedding graphene oxide nanoplates, J. Membr. Sci., 2014, 453, 292-301.

97 K. Guan, D. Zhao, M. Zhang, J. Shen, G. Zhou, G. Liu, et al. 3D nanoporous crystals enabled 2D channels in graphene membrane with enhanced water purification performance, J. Membr. Sci., 2017, 542, 41-51.

98 M. Zhang, K. Guan, J. Shen, G. Liu, Y. Fan and W. Jin, Nanoparticles@ rGO membrane enabling highly 
enhanced water permeability and structural stability with preserved selectivity, AIChE J., 2017, 63(11), 5054-5063.

99 P. Sun, M. Zhu, K. Wang, M. Zhong, J. Wei, D. Wu, et al. Selective ion penetration of graphene oxide membranes, ACS Nano, 2012, 7(1), 428-437.

100 Y. Zhang, S. Zhang and T.-S. Chung, Nanometric graphene oxide framework membranes with enhanced heavy metal removal via nanofiltration, Environ. Sci. Technol., 2015, 49(16), 10235-10242.

101 W. Hu, C. Peng, W. Luo, M. Lv, X. Li, D. Li, et al. Graphenebased antibacterial paper, ACS Nano, 2010, 4(7), 4317-4323.

102 S. Liu, T. H. Zeng, M. Hofmann, E. Burcombe, J. Wei, R. Jiang, et al. Antibacterial activity of graphite, graphite oxide, graphene oxide, and reduced graphene oxide: membrane and oxidative stress, ACS Nano, 2011, 5(9), 6971-6980.

103 R. Kanchanapally, B. P. V. Nellore, S. S. Sinha, F. Pedraza, S. J. Jones, A. Pramanik, et al. Antimicrobial peptideconjugated graphene oxide membrane for efficient removal and effective killing of multiple drug resistant bacteria, RSC Adv., 2015, 5(24), 18881-18887.

$104 \mathrm{X}$. Feng and R. Y. M. Huang, Liquid separation by membrane pervaporation: a review, Ind. Eng. Chem. Res., 1997, 36(4), 1048-1066.

105 P. Shao and R. Y. M. Huang, Polymeric membrane pervaporation, J. Membr. Sci., 2007, 287(2), 162-179.

106 K. Huang, G. Liu, Y. Lou, Z. Dong, J. Shen and W. Jin, A graphene oxide membrane with highly selective molecular separation of aqueous organic solution, Angew. Chem., Int. Ed., 2014, 53(27), 6929-6932.

107 K. Huang, G. Liu, J. Shen, Z. Chu, H. Zhou, X. Gu, et al. High-efficiency water-transport channels using the synergistic effect of a hydrophilic polymer and graphene oxide laminates, Adv. Funct. Mater., 2015, 25(36), 58095815 .

108 R. L. G. Lecaros, G. E. J. Mendoza, W.-S. Hung, Q.-F. An, A. R. Caparanga, H.-A. Tsai, et al. Tunable interlayer spacing of composite graphene oxide-framework membrane for acetic acid dehydration, Carbon, 2017, 123, 660-667.

109 D. Hua, R. K. Rai, Y. Zhang and T.-S. Chung, Aldehyde functionalized graphene oxide frameworks as robust membrane materials for pervaporative alcohol dehydration, Chem. Eng. Sci., 2017, 161, 341-349.

110 W.-S. Hung, S.-M. Chang, R. L. G. Lecaros, Y.-L. Ji, Q.-F. An, C.-C. $\mathrm{Hu}$, et al. Fabrication of hydrothermally reduced graphene oxide/chitosan composite membranes with a lamellar structure on methanol dehydration, Carbon, 2017, 117, 112-119.

111 E. N. Wang and R. Karnik, Water desalination: graphene cleans up water, Nat. Nanotechnol., 2012, 7(9), 552.

112 D. Konatham, J. Yu, T. A. Ho and A. Striolo, Simulation insights for graphene-based water desalination membranes, Langmuir, 2013, 29(38), 11884-11897.

113 H. M. Hegab and L. Zou, Graphene oxide-assisted membranes: fabrication and potential applications in desalination and water purification, J. Membr. Sci., 2015, 484, 95-106.

114 T. Y. Cath, A. E. Childress and M. Elimelech, Forward osmosis: principles, applications, and recent developments, J. Membr. Sci., 2006, 281(1-2), 70-87.

115 R. W. Holloway, A. E. Childress, K. E. Dennett and T. Y. Cath, Forward osmosis for concentration of anaerobic digester centrate, Water Res., 2007, 41(17), 4005-4014.

116 A. Nicolaï, B. G. Sumpter and V. Meunier, Tunable water desalination across graphene oxide framework membranes, Phys. Chem. Chem. Phys., 2014, 16(18), 86468654.

117 M. Fathizadeh, H. N. Tien, K. Khivantsev, Z. Song, F. Zhou and M. Yu, Polyamide/nitrogen-doped graphene oxide quantum dots (N-GOQD) thin film nanocomposite reverse osmosis membranes for high flux desalination, Desalination, 2017, in press, corrected proof.

118 Y. Shi, C. Li, D. He, L. Shen and N. Bao, Preparation of graphene oxide-cellulose acetate nanocomposite membrane for high-flux desalination, J. Mater. Sci., 2017, 52(22), 13296-13306.

119 B. Feng, K. Xu and A. Huang, Synthesis of graphene oxide/ polyimide mixed matrix membranes for desalination, $R S C$ Adv., 2017, 7(4), 2211-2217.

120 S. G. Kim, D. H. Hyeon, J. H. Chun, B.-H. Chun and S. H. Kim, Novel thin nanocomposite RO membranes for chlorine resistance, Desalin. Water Treat., 2013, 51(31-33), 6338-6345.

121 J. Shi, W. Wu, Y. Xia, Z. Li and W. Li, Confined interfacial polymerization of polyamide-graphene oxide composite membranes for water desalination, Desalination, 2018, 441, 77-86.

122 X. Qian, N. Li, Q. Wang and S. Ji, Chitosan/graphene oxide mixed matrix membrane with enhanced water permeability for high-salinity water desalination by pervaporation, Desalination, 2018, 438, 83-96.

123 M. Safarpour, A. Khataee and V. Vatanpour, Thin film nanocomposite reverse osmosis membrane modified by reduced graphene oxide/ $\mathrm{TiO}_{2}$ with improved desalination performance, J. Membr. Sci., 2015, 489, 43-54.

124 B. Jia and L. Zou, Graphene nanosheets reduced by a multistep process as high-performance electrode material for capacitive deionisation, Carbon, 2012, 50(6), 2315-2321.

125 L. Chen, J.-H. Moon, X. Ma, L. Zhang, Q. Chen, L. Chen, et al. High performance graphene oxide nanofiltration membrane prepared by electrospraying for wastewater purification, Carbon, 2018, 130, 487-494.

126 S.-C. Wei, S. Fan, C.-W. Lien, B. Unnikrishnan, Y.-S. Wang, H.-W. Chu, et al. Graphene oxide membrane as an efficient extraction and ionization substrate for spray-mass spectrometric analysis of malachite green and its metabolite in fish samples, Anal. Chim. Acta, 2018, 1003, 42-48.

127 K. Li, B. Wang, J. Y. Chong and C. Mattevi, Dynamic microstructure of graphene oxide membranes and the permeation flux, J. Membr. Sci., 2018, 549, 385-392. 
128 A. Abdel-Karim, S. Leaper, M. Alberto, A. Vijayaraghavan, X. Fan, S. M. Holmes, et al. High flux and fouling resistant flat sheet polyethersulfone membranes incorporated with graphene oxide for ultrafiltration applications, Chem. Eng. J., 2018, 334, 789-799.

129 H. Kang, J. Shi, L. Liu, M. Shan, Z. Xu, N. Li, et al. Sandwich morphology and superior dye-removal performances for nanofiltration membranes self-assembled via graphene oxide and carbon nanotubes, Appl. Surf. Sci., 2018, 428, 990-999.

130 Y. Zhan, X. Wan, S. He, Q. Yang and Y. He, Design of durable and efficient poly (arylene ether nitrile)/ bioinspired polydopamine coated graphene oxide nanofibrous composite membrane for anionic dyes separation, Chem. Eng. J., 2018, 333, 132-145.

131 J. Ma, Y. He, G. Zeng, F. Li, Y. Li, J. Xiao, et al. Bio-inspired method to fabricate poly-dopamine/reduced graphene oxide composite membranes for dyes and heavy metal ion removal, Polym. Adv. Technol., 2018, 29(2), 941-950.

132 Y. Liu, W. Tu, M. Chen, L. Ma, B. Yang, Q. Liang, et al. A mussel-induced method to fabricate reduced graphene oxide/halloysite nanotubes membranes for multifunctional applications in water purification and oil/ water separation, Chem. Eng. J., 2018, 336, 263-277.

133 E. Bagheripour, A. R. Moghadassi, S. M. Hosseini, B. Van der Bruggen and F. Parvizian, Novel composite graphene oxide/chitosan nanoplates incorporated into PES based nanofiltration membrane: chromium removal and antifouling enhancement, J. Ind. Eng. Chem., 2018, 62, 311-320.

134 Q. Zhang, S. Chen, X. Fan, H. Zhang, H. Yu and X. Quan, A multifunctional graphene-based nanofiltration membrane under photo-assistance for enhanced water treatment based on layer-by-layer sieving, Appl. Catal., B, 2018, 224, 204-213.

135 H. Wang, W. Wang, L. Wang, B. Zhao, Z. Zhang, X. Xia, et al. Enhancement of hydrophilicity and the resistance for irreversible fouling of polysulfone (PSF) membrane immobilized with graphene oxide (GO) through chloromethylated and quaternized reaction, Chem. Eng. J., 2018, 334, 2068-2078.

136 Z. Liu, W. Wu, Y. Liu, C. Qin, M. Meng, Y. Jiang, et al. A mussel inspired highly stable graphene oxide membrane for efficient oil-in-water emulsions separation, Sep. Purif. Technol., 2018, 199, 37-46.

137 L.-C. Lin and J. C. Grossman, Atomistic understandings of reduced graphene oxide as an ultrathin-film nanoporous membrane for separations, Nat. Commun., 2015, 6, 8335.

138 C. Chi, X. Wang, Y. Peng, Y. Qian, Z. Hu, J. Dong, et al. Facile preparation of graphene oxide membranes for gas separation, Chem. Mater., 2016, 28(9), 2921-2927.

139 S. Wang, Y. Wu, N. Zhang, G. He, Q. Xin, X. Wu, et al. A highly permeable graphene oxide membrane with fast and selective transport nanochannels for efficient carbon capture, Energy Environ. Sci., 2016, 9(10), 3107-3112.
140 J. Shen, M. Zhang, G. Liu, K. Guan and W. Jin, Size effects of graphene oxide on mixed matrix membranes for $\mathrm{CO}_{2}$ separation, AIChE J., 2016, 62(8), 2843-2852.

141 Y. Hu, J. Wei, Y. Liang, H. Zhang, X. Zhang, W. Shen, et al. Zeolitic imidazolate framework/graphene oxide hybrid nanosheets as seeds for the growth of ultrathin molecular sieving membranes, Angew. Chem., Int. Ed., 2016, 55(6), 2048-2052.

142 M. Jia, Y. Feng, S. Liu, J. Qiu and J. Yao, Graphene oxide gas separation membranes intercalated by UiO-66- $\mathrm{NH}_{2}$ with enhanced hydrogen separation performance, J. Membr. Sci., 2017, 539, 172-177.

143 H. Ha, J. Park, S. Ando, K. C. Bin, K. Nagai, B. D. Freeman, et al. Gas permeation and selectivity of poly (dimethylsiloxane)/graphene oxide composite elastomer membranes, J. Membr. Sci., 2016, 518, 131-140.

144 L. Dong, M. Chen, J. Li, D. Shi, W. Dong, X. Li, et al. Metalorganic framework-graphene oxide composites: A facile method to highly improve the $\mathrm{CO}_{2}$ separation performance of mixed matrix membranes, J. Membr. Sci., 2016, 520, 801-811.

145 J. Deng, Y. You, H. Bustamante, V. Sahajwalla and R. K. Joshi, Mechanism of water transport in graphene oxide laminates, Chem. Sci., 2017, 8(3), 1701-1704.

146 M. Majumder, N. Chopra, R. Andrews and B. J. Hinds, Nanoscale hydrodynamics: enhanced flow in carbon nanotubes, Nature, 2005, 438(7064), 44.

147 K. Falk, F. Sedlmeier, L. Joly, R. R. Netz and L. Bocquet, Molecular origin of fast water transport in carbon nanotube membranes: superlubricity versus curvature dependent friction, Nano Lett., 2010, 10(10), 4067-4073.

148 A. Striolo, The mechanism of water diffusion in narrow carbon nanotubes, Nano Lett., 2006, 6(4), 633-639.

149 G. Algara-Siller, O. Lehtinen, F. C. Wang, R. R. Nair, U. Kaiser, H. A. Wu, et al. Square ice in graphene nanocapillaries, Nature, 2015, 519(7544), 443.

150 L. Staudenmaier, Verfahren zur darstellung der graphitsäure, Eur. J. Inorg. Chem., 1898, 31(2), 1481-1487.

151 Y. Su, V. G. Kravets, S. L. Wong, J. Waters, A. K. Geim and R. R. Nair, Impermeable barrier films and protective coatings based on reduced graphene oxide, Nat. Commun., 2014, 5, 4843.

152 J. G. Wijmans and R. W. Baker, The solution-diffusion model: a review, J. Membr. Sci., 1995, 107(1-2), 1-21.

153 M. S. H. Boutilier, N. G. Hadjiconstantinou and R. Karnik, Knudsen effusion through polymer-coated three-layer porous graphene membranes, Nanotechnology, 2017, 28(18), 184003.

154 J. Mulder, Basic principles of membrane technology, Springer Science \& Business Media, 2012.

155 M. Knudsen, Die Gesetze der Molekularströmung und der inneren Reibungsströmung der Gase durch Röhren, Ann. Phys., 1909, 333(1), 75-130.

156 K. Guan, J. Shen, G. Liu, J. Zhao, H. Zhou and W. Jin, Sprayevaporation assembled graphene oxide membranes for selective hydrogen transport, Sep. Purif. Technol., 2017, 174, 126-135. 
157 S. Gadipelli and Z. X. Guo, Graphene-based materials: synthesis and gas sorption, storage and separation, Prog. Mater. Sci., 2015, 69, 1-60.
158 A. Ibrahim and Y. S. Lin, Gas Permeation and Separation Properties of Large-Sheet Stacked Graphene Oxide Membranes, J. Membr. Sci., 2017, 550, 238-245. 